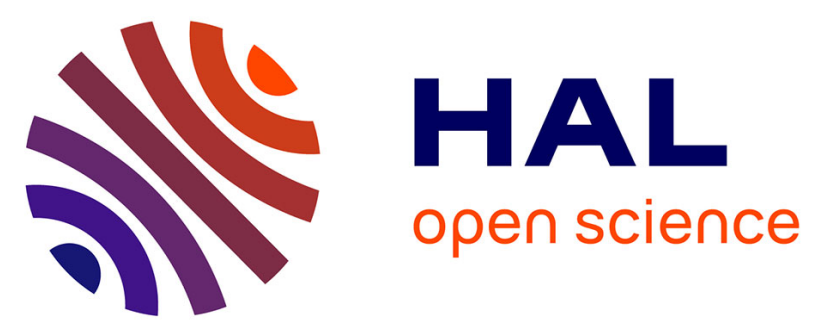

\title{
Cooperative interaction of benzo[a]pyrene and ethanol on plasma membrane remodeling is responsible for enhanced oxidative stress and cell death in primary rat hepatocytes.
}

Aurore Collin, Kevin Hardonnière, Martine Chevanne, Julie Vuillemin, Normand Podechard, Agnès Burel, Marie-Thérèse Dimanche-Boitrel, Dominique Lagadic-Gossmann, Odile Sergent

\section{- To cite this version:}

Aurore Collin, Kevin Hardonnière, Martine Chevanne, Julie Vuillemin, Normand Podechard, et al.. Cooperative interaction of benzo[a]pyrene and ethanol on plasma membrane remodeling is responsible for enhanced oxidative stress and cell death in primary rat hepatocytes.. Free Radical Biology and Medicine, 2014, 72, pp.11-22. 10.1016/j.freeradbiomed.2014.03.029 . hal-01018147

HAL Id: hal-01018147

https://hal-univ-rennes1.archives-ouvertes.fr/hal-01018147

Submitted on 3 Jul 2014

HAL is a multi-disciplinary open access archive for the deposit and dissemination of scientific research documents, whether they are published or not. The documents may come from teaching and research institutions in France or abroad, or from public or private research centers.
L'archive ouverte pluridisciplinaire HAL, est destinée au dépôt et à la diffusion de documents scientifiques de niveau recherche, publiés ou non, émanant des établissements d'enseignement et de recherche français ou étrangers, des laboratoires publics ou privés. 


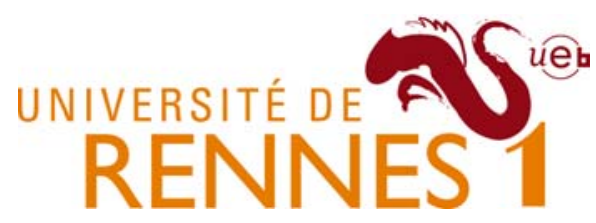

This is the author's final draft post-refeering (post-print)

Find more peer-reviewed articles on our open access repository:

http://hal-univ-rennes1.archives-ouvertes.fr/ 
Cooperative interaction of benzo[a]pyrene and ethanol on plasma membrane remodeling is responsible for enhanced oxidative stress and cell death in primary rat hepatocytes

Aurore Collin ${ }^{1,2}$, Kevin Hardonnière ${ }^{1,2}$, Martine Chevanne ${ }^{1,2}$, Julie Vuillemin ${ }^{1,2}$, Normand Podechard $^{1,2}$, Agnès Burel ${ }^{2}$, Marie-Thérèse Dimanche-Boitrel ${ }^{1,2}$, Dominique Lagadic-Gossmann*1,2 and Odile Sergent*1,2

${ }^{1}$ : UMR Inserm 1085, IRSET, UFR des Sciences Pharmaceutiques et Biologiques, 2, av Pr Léon Bernard, 35043 Rennes cédex, France

2 : Université de Rennes 1, Biosit UMS3080, 2, av Pr Léon Bernard, 35043 Rennes cédex, France

*: these authors contributed equally as last authors

\section{Corresponding authors :}

Dominique Lagadic-Gossmann (DLG) and Odile Sergent (OS)

Address : UMR Inserm 1085, IRSET, Université de Rennes 1, UFR des Sciences

Pharmaceutiques et Biologiques, 2, av Pr Léon Bernard, 35043 Rennes cédex, France

Telephone number : 33(0)223234837 (DLG) and 33(0)223234808(OS)

Fax number : 33(0)223234794

E-mail address : dominique.lagadic@univ-rennes1.fr and osergent@univ-rennes1.fr 


\section{Abstract}

Several epidemiologic studies have shown an interactive effect of heavy smoking and alcohol heavy drinking on the development of hepatocellular carcinoma. It has also been recently described that chronic hepatocyte death can trigger excessive compensatory proliferation resulting later in the formation of tumors in mice liver. As we previously demonstrated that both benzo[a]pyrene $(\mathrm{B}[\mathrm{a}] \mathrm{P})$, environmental agent found in cigarette smoke, and ethanol alone possessed similar targets, especially oxidative stress, to trigger death of liver cells, we presently decided to study the cellular and molecular mechanisms of the effect of $\mathrm{B}[\mathrm{a}] \mathrm{P} /$ ethanol co-exposure on cell death. After an 18-hours incubation time with $100 \mathrm{nM}$ $\mathrm{B}[\mathrm{a}] \mathrm{P}$, primary rat hepatocytes were supplemented with $50 \mathrm{mM}$ ethanol for 5 or 8 hours. $\mathrm{B}[\mathrm{a}] \mathrm{P} /$ ethanol co-exposure led to a greater apoptotic cell death that could be linked to an increase in lipid peroxidation. Plasma membrane remodeling, as depicted by a membrane fluidity elevation and physicochemical alterations of lipid rafts, appeared to play a key role, since both toxicants acted with specific complementary effects. Membrane remodeling was shown to induce an accumulation of lysosomes leading to an important increase in low molecular weight iron cellular content. Finally, ethanol metabolism, but not B[a]P, by providing ROS, induced the ultimate toxic process. Indeed, in lysosomes, ethanol promoted Fenton reaction, lipid peroxidation and membrane permeabilization thereby triggering cell death. To conclude, B[a]P exposure, by depleting cholesterol membrane content of hepatocytes, would constitute a favorable ground for a later toxic aggression such as ethanol intoxication. Membrane stabilization of both plasma membrane and lysosomes might be a potential target for further investigation considering cytoprotective strategies.

\section{Key words :}

Benzo[a]pyrene, ethanol, liver, primary rat hepatocytes, oxidative stress, iron, reactive oxygen species, lysosome, membrane fluidity, lipid rafts. 


\section{Introduction}

Polycyclic aromatic hydrocarbons (PAHs) are widespread environmental agents formed during the incomplete combustion or pyrolysis of organic matter. Thus, they are found in ambient air, cigarette smoke, grilled and smoked food, so that humans are continuously exposed to these compounds by the inhalation and oral route. Among PAHs, benzo[a]pyrene $(\mathrm{B}[\mathrm{a}] \mathrm{P})$ is the most thoroughly studied because of its ubiquitous presence in $\mathrm{PAH}$ mixtures in the environment and in food (1-3). Because of the strong evidence of its carcinogenicity in animals and of its genotoxicity in exposed humans, $\mathrm{B}[\mathrm{a}] \mathrm{P}$ is now recognized as a human carcinogen from group 1 by the International Agency for Research on Cancer (1). Focusing more on liver cancer, meta-analysis of epidemiologic studies indicated that tobacco smoking could be associated with hepatocellular carcinoma (4). In addition, subjects with elevated PAH metabolites-DNA adduct levels in the liver appear to exhibit a higher risk for hepatocellular carcinoma (5). Although the etiology of $\mathrm{B}[\mathrm{a}] \mathrm{P}$-induced tumor initiation is very complex, three bulk mechanisms for this initiation can be put forward. First, although chemically inert, $\mathrm{B}[\mathrm{a}] \mathrm{P}$ undergoes metabolic activation to diol-epoxides within mammalian cells, which then bind covalently to cellular macromolecules, such as DNA $(6,7)$. Second, during the metabolic process, $\mathrm{B}[\mathrm{a}] \mathrm{P}$ produces reactive oxygen species that can cause oxidative DNA damage (8). Both events can then start the mutagenic chain of events responsible for tumor initiation. Third, B[a]P can induce apoptotic death of liver cells $(9,10)$. Considering this latter point, it has been recently described that recurrent aggression of the liver leading to chronic hepatocyte death can trigger excessive compensatory proliferation resulting later in the formation of tumors in mice liver (11-13). Consequently, thorough analyses of $\mathrm{B}[\mathrm{a}] \mathrm{P}$-induced cell death will provide new insights in the pathogenic process for the tumor initiation in the liver. In this context, during the last decade, our team has been focusing its research on deciphering the mechanisms underlying the $\mathrm{B}[\mathrm{a}] \mathrm{P}$-induced death of 
liver cells, and has already demonstrated the involvement of both oxidative stress $(14,15)$ and plasma membrane remodeling, especially changes in membrane fluidity (16) and in physicochemical characteristics of lipid rafts $(17,18)$. Besides, we also found that membrane fluidity (19) and lipid rafts $(20,21)$ were involved in ethanol-induced oxidative stress and apoptosis of primary rat hepatocytes. Interestingly, several epidemiologic studies have shown an interactive effect of heavy smoking and heavy drinking on the development of hepatocellular carcinoma $(22,23)$; but the underlying molecular mechanisms still remain unknown, even if similar roles in hepatocellular carcinoma development have been pointed out for each exposure type (24). As we previously found that both $\mathrm{B}[\mathrm{a}] \mathrm{P}$ and ethanol alone possessed similar targets in liver cells, we presently decided to study the cellular and molecular mechanisms of the effect of the $\mathrm{B}[\mathrm{a}] \mathrm{P} / \mathrm{ethanol}$ co-exposure on cell death by focusing on oxidative stress and membrane remodeling. In primary rat hepatocytes, $\mathrm{B}[\mathrm{a}] \mathrm{P} / \mathrm{ethanol}$ co-exposure was found, for the first time in hepatocytes, to increase cell death when compared to toxicants alone. This could be related to oxidative stress and membrane remodeling, via a mechanism that involved lysosome permeabilization. 


\section{Materials and methods}

\section{Chemicals}

Eagle minimum medium and medium 199 with Hanks' salts were purchased from Gibco, Invitrogen (Cergy-Pontoise, France). Bovine serum albumin and fetal calf serum were purchased from Biowest (Nuaille, France). Liberase was from Roche Diagnostics (Meylan, France). Ethanol was obtained from Prolabo (Paris, France). Acridine orange, $\alpha$ naphthoflavone $(\alpha \mathrm{NF})$, bafilomycin, benzo[a]pyrene, cholesterol oxidase (CHOX), cholesterol water soluble, N-Acetyl-Asp-Glu-Val-Asp-7-amido-4-methylcoumarin (AcDEVD AMC), diallylsulfide (DAS), 12-doxylstearic acid (12-DSA), Hoechst 33342, 4methylpyrazole (4-MP), 2-nitro-4-carboxyphenyl- $N, N$-diphenylcarbamate (NCDC), pepstatin A, thiazolyl tetrazolium blue bromide (MTT), thiourea and $\alpha$-tocopherol (vitamin E) were provided from Sigma-Aldrich. Deferiprone was from Acros (Fischer, Illkirch, France). Leucine-leucyl-O-methyl-HBr (LLoMe) was purchased from Bachem (Bubendorf, Switzerland). Ursodeoxycholate sodium salt (UDCA) and n-benzyloxycarbonyl-Val-AlaAsp(O-Me) fluoromethyl ketone (Z-VAD) were purchased from Calbiochem (Millipore, Saint-Quentin Les Yvelines, France). 4,4-difluoro-5-(4-phenyl-1,3-butadienyl)-4-bora-3a,4adiaza-s-indacene-3-undecanoic acid (BODIPY® 581/591 C11), dihydrofluorescein diacetate $\left(\mathrm{H}_{2} \mathrm{FDA}\right)$ and cholera toxin subunit B (Recombinant), Alexa Fluor ${ }^{\circledR} 488$ Conjugate were provided by Molecular Probes (Invitrogen, Cergy-Pontoise, France). CellTiter-Glo® Luminescent Cell Viability Assay was from Promega (Charbonnières, France). LDHcytotoxicity assay kit II was provided by Abcam (Paris, France). InfinityTM cholesterol reagent was purchased from Thermo Scientific (Thermo Fisher Scientific, Courtaboeuf, France). Anti-mouse immunoglobulin $\mathrm{G}(\mathrm{IgG})$ was from DAKO (Trappes, France). Anti- 
phospholipase $\mathrm{C} \gamma 1$ antibody was purchased from Upstate (Millipore, Saint-Quentin-Les Yvelines, France). Flotillin-1 was obtained from BD Biosciences (Le Pont de Claix, France).

\section{Cell isolation and culture}

Adult rat hepatocytes were isolated from 2-month-old Sprague-Dawley animals by perfusion of the liver as previously described, except that a $17 \mu \mathrm{g} / \mathrm{ml}$ liberase solution was used for dissociation (25). Routinely, cell viability was above $80 \%$.

Cells were seeded at densities of $30 \times 10^{3}$ cells/well in 96-well Falcon microplates (MTT assay, ATP content, LDH release, ROS and lipid peroxidation evaluation), 1 x $10^{6}$ cells in 35-mm Petri dish (Hoechst 33342 staining), $3 \times 10^{6}$ cells in $60-\mathrm{mm}$ Petri dish (caspase 3/7 activity, LDH release), $10 \times 10^{6}$ cells in $100 \mathrm{~mm}$ Petri dish (membrane fluidity determination), and $20 \times 10^{6}$ cells in $150-\mathrm{mm}$ Petri dish (low molecular weight iron measurement and lipid raft isolation); they were then cultured in a medium composed of $75 \%$ minimum Eagle's medium and 25\% medium 199 with Hanks' salts, supplemented with 10\% fetal calf serum and containing $50 \mu \mathrm{g}$ streptomycin, $5 \mu \mathrm{g}$ penicillin, $5 \mu \mathrm{g}$ bovine insulin, $1 \mathrm{mg}$ bovine serum albumin, and $2.2 \mathrm{mg} \mathrm{NaHCO}_{3}$ per milliliter. The cells were kept at $37^{\circ} \mathrm{C}$ in an atmosphere of $5 \% \mathrm{CO}_{2}$ and $95 \%$ air. The medium was changed $3 \mathrm{~h}$ after seeding and substituted with the same medium as above but deprived of serum. Benzo[a]pyrene was added to the medium at a final concentration of $100 \mathrm{nM}$ to rat hepatocytes. After an 18-hours incubation time at $37^{\circ} \mathrm{C}$, some cultures were then supplemented with $50 \mathrm{mM}$ ethanol for 5 or 8 hours, and untreated cultures (supplemented with $0.005 \%$ DMSO) were used as controls. These incubation times were chosen because we previously demonstrated a maximal cytotoxicity at 24 hours for B[a]P (26), and 5 hours for ethanol (19).

\section{Cytotoxicity determination}




\section{Cell viability}

Metabolically active viable hepatocytes were evaluated both by the mitochondrial succinate dehydrogenase activity using a MTT assay and by the ATP content. Succinate dehydrogenase activity and ATP content were considered to be directly proportional to the number of cells in the culture.

MTT assay. MTT is a tetrazolium salt that is reduced to purple formazan crystals mainly by mitochondrial succinate dehydrogenase. Briefly, after discarding culture medium, hepatocytes were incubated for two hours with $0.5 \mathrm{mg} / \mathrm{mL}$ MTT. After MTT removal, formazan crystals were then solubilized in DMSO. Using a microplate reader (SPECTROSTAR Omega, BMG Labtech), absorbance was directly measured at $560 \mathrm{~nm}$ and $630 \mathrm{~nm}$ reference. For each sample, values from the $560 \mathrm{~nm}$ absorbance was subtracted from $630 \mathrm{~nm}$ to negate the background effect. Cell treatment with drug vehicle was considered $100 \%$ of viability.

ATP content. ATP content was evaluated using a luminescent assay kit based upon the reaction of luciferin with ATP in presence of luciferase (CellTiter-Glo® luminescent Cell Viability Assay, Promega), according to manufacturer instructions. The amount of ATP was proportional to the luminescent signal measured with a spectrophotometer (SpectraMax Gemini; Molecular Devices, France).

\section{Cell death}

Cell death was tested for both apoptotic and necrotic cell death.

Visualization of chromatin condensation and fragmentation by nuclear staining. Chromatin condensation and morphological changes in the nucleus were observed using the chromatin dye Hoechst 33342. After treatments, cells were stained with $50 \mu \mathrm{g} / \mathrm{ml}$ Hoechst 33342 in the dark for $30 \mathrm{~min}$ at $37^{\circ} \mathrm{C}$. Fluorescence was stabilized using FluorSave ${ }^{\mathrm{TM}}$ Reagent (Merck 
Millipore). Cells were then examined under fluorescence microscopy (Olympus BX60, France). Total population was always more than 400 cells.

Measurement of caspase-3/7 activity. To determine caspases-3/7 activity, hepatocytes were lysed in the caspase activity buffer (27). Eighty micrograms of crude cell lysate were incubated with $80 \mu \mathrm{M}$ DEVD-AMC for $2 \mathrm{~h}$ at $37^{\circ} \mathrm{C}$. Caspase-mediated cleavage of DEVDAMC was measured by spectrofluorimetry (Spectramax Gemini; Molecular Devices) using $380 \mathrm{~nm}$ excitation and $440 \mathrm{~nm}$ emission wavelengths.

LDH leakage. Necrotic cell death is characterized by plasma membrane damage, thereby leading to the release of intracellular enzymes to the extracellular medium. Lactate dehydrogenase (LDH) leakage was thus measured by using the LDH-Cytotoxicity Assay Kit II (Abcam) based upon an enzymatic coupling reaction : LDH by oxidizing lactate produces $\mathrm{NADH}$, which then reacts with WST to generate yellow color. Briefly, after adding manufacturer reactant, yellow color was quantified at $450 \mathrm{~nm}$ for 45 minutes at $37{ }^{\circ} \mathrm{C}$ by spectrophotometer (SPECTROSTAR Omega, BMG Labtech), both in culture medium and in cells. The background value at $650 \mathrm{~nm}$ was subtracted from the values à $450 \mathrm{~nm}$ for each sample, in order to negate the effect of cell debris and precipitated proteins. LDH leakage was then quantified by calculating the ratio of extracellular LDH/total LDH.

\section{Ultrastructural changes}

Transmission electron microscopy (TEM). Following drug exposure, the cells were rinsed with $0.15 \mathrm{M} \mathrm{Na}$ cacodylate buffer and fixed by drop wise addition of glutaraldehyde $(2.5 \%)$ for 1 hour. After fixation, the specimens were rinsed several times with $0.15 \mathrm{M} \mathrm{Na}$ cacodylate buffer and post fixed with $1.5 \%$ osmium tetroxide for 1 hour. After further rinsing with cacodylate buffer, the samples were dehydrated through a series of graded ethanol from 70 to $100 \%$. The specimens were infiltrated in a mixture of acetone-Eponate $(50 / 50)$ for $3 \mathrm{~h}$, then in pure Eponate for $16 \mathrm{~h}$. Finally, the specimens were embedded in DMP30-Eponate for $24 \mathrm{~h}$ 
at $60{ }^{\circ} \mathrm{C}$. Sections $(0.5 \mu \mathrm{m})$ were cut on a LEICA UC7 microtome and stained with toluidine blue. Ultra-thin sections $(90 \mathrm{~nm})$ were obtained, collected onto copper grids and counterstained with $4 \%$ uranyl acetate then with lead citrate. Examination was performed with JEOL 1400 transmission electron microscope operated at $120 \mathrm{kV}$.

Lysosomal membrane permeabilization. Lysosome disruption was estimated from acridine orange-stained hepatocytes knowing that an increase in green acridine orange fluorescence reflected such a disruption. Briefly, after 18 hours of $\mathrm{B}[\mathrm{a}] \mathrm{P}$ treatment, supernatant was removed apart and cultures were incubated with acridine orange $(5 \mu \mathrm{M})$ for 15 minutes at $37^{\circ} \mathrm{C}$. After a short wash, cells were treated with ethanol for 1 or 5 hours, and then analyzed by flow cytometry on a FACS calibur flow cytometer (Becton Dickinson, San Jose, USA). Fluorescence emission of acridine orange was detected at FL1 (Green acridine orange fluorescence) following excitation at $488 \mathrm{~nm}$. Each measurement was conducted on 50000 events and analyzed on Cell Quest software (Becton Dickinson).

\section{Oxidative stress evaluation}

\section{Determination of reactive oxygen species production}

Intracellular levels of reactive oxygen species (ROS) were measured using the nonfluorescent probe, dihydrofluorescein diacetate $\left(\mathrm{H}_{2} \mathrm{FDA}\right)$, as previously described (19). Oxidation by ROS causes a conversion of this probe into fluorescent fluorescein. Fluorescence was directly recorded by a SpectraMax Gemini spectrofluorimeter (Molecular Devices, France) using 485 $\mathrm{nm}$ excitation and $530 \mathrm{~nm}$ emission wavelengths. Even though several limitations have been described for this probe such as a lack of selectivity for ROS detection, a possible oxidation by reactive nitrogen species or proteins without ROS production and a light dependent-autooxidation (28), we decided to use it because of its simplicity and the low cell quantity needed.

\section{Evaluation of lipid peroxidation}


As previously described (19), lipid peroxidation was measured using the fluoroprobe C11BODIPY $^{581 / 591}$ that incorporates into cell membranes and is sensitive to oxidation. C11BODIPY $^{581 / 591}$ shifts from red to green fluorescence upon oxidation. Briefly, fluorescence was recorded by a SpectraMax Gemini spectrofluorimeter (Molecular Devices) using two pairs of wavelengths to measure the amount of reduced ( $\lambda$ ex $590 \mathrm{~nm}, \lambda$ em $635 \mathrm{~nm}$ ) and oxidized probe ( $\lambda$ ex $485 \mathrm{~nm}, \lambda$ em $535 \mathrm{~nm}$ ). Lipid peroxidation was then quantified by calculating the ratio of oxidized probe/ total probe.

\section{Measurement of low molecular weight iron}

Measurement of intracellular low molecular weight (LMW) iron was based upon the capacity of deferiprone to chelate only LMW iron and to give a paramagnetic chelate, which can be directly detectable by EPR in whole hepatocytes (29).

\section{Membrane remodeling characterization}

Membrane remodeling was estimated by the evaluation of bulk membrane fluidity and both physical and chemical alterations of lipid rafts.

\section{Membrane fluidity}

Membrane fluidity was measured, as previously described (19), in bulk membranes (i.e., plasma membrane and possibly endosome and lysosome membranes) of hepatocytes. Membranes were spin labeled by incubating hepatocyte suspensions at $37^{\circ} \mathrm{C}$ for 15 minutes with 12-doxyl stearic acid $(50 \mu \mathrm{g} / \mathrm{ml})$. The EPR spectra of labeled samples were acquired at ambient temperature on a Brucker Elexsys EPR spectrometer operating at $3509 \mathrm{G}$ center field, $20 \mathrm{~mW}$ microwave power, $9.86 \mathrm{GHz}$ microwave frequency, $1.77 \mathrm{G}$ modulation amplitude and $100 \mathrm{kHz}$ modulation frequency. The fluidity of the labeled membrane was quantified by calculating the order parameter $\mathrm{S}$, which is inversely related to membrane fluidity. 


\section{Lipid raft fractionation by flotation method}

Lipid rafts are defined as being resistant to solubilization by nonionic detergents at low temperature and able to float and concentrate in low-density fractions of a sucrose gradient after ultracentrifugation, as previously described (20). Briefly, lysates were centrifuged at $39,000 \mathrm{rpm}$ for 20 hours at $4{ }^{\circ} \mathrm{C}$ in a SW41 rotor, allowing eleven $1-\mathrm{ml}$ fractions to be collected from the top of the gradient for protein and lipid analysis. The 1 to 6 fractions contained lipid rafts, as previously characterized (20). In some experiments, the whole raft fractions (fractions 1 to 6) were gathered, diluted in PBS and pelleted by another ultracentrifugation at $41000 \mathrm{rpm}$ for $16-20$ hours at $4{ }^{\circ} \mathrm{C}$ in a SW41 rotor. This last procedure allowed us to pool lipid rafts in a single pellet.

\section{Protein assays in lipid raft fractions}

Flotillin-1 and phospholipase $\mathrm{C} \gamma 1$ (PLC $\gamma 1$ ) were determined using SDS polyacrylamide gel electrophoresis and western blot analysis. For each gradient fraction, 2 to $5 \mu \mathrm{g}$, for flotillin and PLC $\gamma 1$ respectively, were separated by a $10 \%$ SDS-polyacrylamide gel electrophoresis. Gel proteins were transferred overnight onto nitrocellulose membranes (Hyblond ECL, Amersham Biosciences Europe, Orsay, France). The membranes were then blocked for 2 hours with Tris-buffered saline (TBS) containing $2 \%$ BSA and $0.1 \%$ Tween 20, at room temperature. For flotillin- 1 and PLC- $\gamma 1$ detection, anti-flotillin- 1 and anti-PLC- $\gamma 1$ at a 1:8000 dilution and 1:1000, respectively, were added first, and the mixture was incubated 2 hours at room temperature. The membrane was then washed three times with $0.1 \%$ Tween 20 in PBS for 30 minutes and incubated in blocking buffer containing conjugated anti-mouse immunoglobulin G secondary antibody at a 1:2000 for 45 minutes. It was then washed three times with $0.1 \%$ Tween 20 in PBS for 15 minutes. Blots were examined using a solution of Tris- $\mathrm{HCl} 0.1 \mathrm{M}$ containing coumaric acid $(0.22 \mathrm{mM})$ and luminol $(1.25 \mathrm{mM})$. 
Alkaline phosphatase activity was determined by a colorimetric method using $p$ nitrophenylphosphate as a substrate, as previously described (20). Briefly, 10 microliters of each fraction were incubated, for 20 minutes at $37^{\circ} \mathrm{C}$, with $90 \mu \mathrm{l}$ PBS and $100 \mu \mathrm{l}$ nitrophenylphosphate ready-to-use liquid reagent (Sigma-Aldrich, Saint Quentin Fallavier, France). The absorbance was measured at $405 \mathrm{~nm}$ using a microplate spectrophotometer (SPECTROSTAR Omega, BMG Labtech).

\section{Fluorescent staining of lipid rafts}

Lipid rafts were stained consecutively to the binding of the cholera toxin subunit B coupled to green-fluorescent Alexa Fluor 488 conjugate to the pentasaccharide chain of the lipid raft marker monosialotetrahexosyl ganglioside (GM1), using the Cholera Toxin Subunit B, Alexa Fluor ${ }^{\circledR} 488$ Conjugate (Molecular Probes, Invitrogen) as previously described (20). Staining was analyzed by conventional fluorescence microscopy using Metavue software. When dual staining was performed, hepatocytes were incubated with both cholera toxin conjugate and the test primary monoclonal anti-phospholipase $C \gamma 1$ antibody $(10 \mu \mathrm{g} / \mathrm{ml})$ for two hours, followed by incubation with 1:2000 TRITC-conjugated anti-mouse immunoglobulin G secondary antibody for an additional two hours. Co-staining was examined by confocal fluorescence microscopy using a LEICA DM 5500 microscope with the Leica LAS AF software.

\section{Statistical analyses}

Data presented were acquired from a minimum of three independent experiments. They are expressed as means \pm S.D. Statistical analyses were performed with a One-Way ANOVA with Newmann-Keuls post-test. All statistical analyses were performed with GraphPad Prism5 software (GraphPad Software, San Diego, CA, USA). The significance is shown as follows: ${ }^{*} \mathrm{p}<0.05, * * \mathrm{p}<0.01$ and $* * * \mathrm{p}<0.001$, treated versus untreated cells. 


\section{Results}

\section{B[a]P/ethanol co-exposure increases cell death of primary rat hepatocytes}

Estimated by the MTT test, B[a]P/ethanol co-exposure was found to lead to a greater decrease in cell viability compared to either treatment alone (Figure 1A). This was confirmed by the decrease in ATP, that was found to be more marked with co-exposure compared to ethanol or $\mathrm{B}[\mathrm{a}] \mathrm{P}$ alone (Figure 1B).

An apoptotic cell death could result from this hepatocyte toxicity of $\mathrm{B}[\mathrm{a}] \mathrm{P} / \mathrm{ethanol}$ coexposure. Indeed, the 5-hours-treatment led only to a slight increase in cell number with condensed or fragmented nuclei (Figure 1C), but with neither significant effect of the coexposure compared to toxicant alone nor elevation of caspase $3 / 7$ activity for any treatment (Figure 1D). By contrast, an 8-hours-co-treatment led to a further elevation of cell number with condensed or fragmented nuclei not only for either toxicant alone (ethanol : $+81 \%$ at 8 hours instead of $+62 \%$ at 5 hours; B[a]P : $+56 \%$ at 8 hours instead of $+36 \%$ at 5 hours), associated with a significant increase in caspase activity (Figure 1C), but also for the coexposure compared to either treatment alone, with a significant increase in apoptotic cell number and caspase 3/7 activity (Figure 1C and 1D). Note that there is a strong increase in apoptotic cell death between 5 hours and 8 hours in control cultures. This is due to the primary culture senescence. Indeed, it is well known that many antioxidant enzymes, such as $\mathrm{Cu}, \mathrm{Zn}$ superoxide dismutase, glutathione peroxidase, or catalase, are less expressed over incubation time after isolation of rat hepatocytes (30), thereby increasing ROS production over incubation time (19). Although the increase in caspase activity remained moderate $(+36$ $\%)$ at 8 hours, the pan caspase inhibitor Z-VAD totally inhibited the increase in the apoptotic cell number (figure 1E), thus pointing to a caspase-dependent apoptotic cell death. In addition, data in Figure $1 \mathrm{~F}$ clearly demonstrated the absence of necrosis whatever the 
condition tested, since no significant increase in the extracellular LDH/total LDH ratio was detected compared to control conditions.

The possible involvement of $\mathrm{B}[\mathrm{a}] \mathrm{P}$ and ethanol metabolism in the observed decrease in cell viability was tested using $\alpha$-naphthoflavone (to inhibit $\mathrm{B}[\mathrm{a}] \mathrm{P}$ metabolism via cytochromes P450 1), 4-methylpyrazole (to inhibit ethanol metabolism via alcohol dehydrogenase and cytochrome P4502E1) and diallylsulfide to inhibit cytochrome P4502E1. These compounds were found to prevent the co-exposure-induced decrease in cell viability (estimated by the MTT test) (Figure 1S). Altogether, these results therefore indicate an increase in cell death level when co-exposing hepatocytes to both $\mathrm{B}[\mathrm{a}] \mathrm{P}$ and ethanol, which involves metabolism of both toxicants.

\section{The toxicity of B[a]P/ethanol co-exposure involves oxidative stress}

As oxidative stress plays an important role in $\mathrm{B}[\mathrm{a}] \mathrm{P}$ or ethanol toxicity alone $(15,20)$, we then decided to evaluate its involvement in the effects of co-exposure. Both vitamin $E$ (a free radical chain-breaking antioxidant) and thiourea (a ROS scavenger), prevented the decrease in cell viability and in ATP content induced by co-exposure (Figures $2 \mathrm{~A}$ and $2 \mathrm{~B}$ ). In addition, co-exposing hepatocytes to $\mathrm{B}[\mathrm{a}] \mathrm{P}$ and ethanol significantly enhanced lipid peroxidation compared to the toxicants alone (Figure 2C). However, no further increase in production of ROS, prooxidant factors, was observed upon co-exposure (Figure 2D). Whereas, as expected, ethanol was found to induce a significant elevation of ROS production, no such a rise was detected with $\mathrm{B}[\mathrm{a}] \mathrm{P}$ alone under our experimental conditions.

\section{LMW iron participates to the toxicity of B[a]P/ethanol co-exposure}

The lack of enhancement of ROS production by the co-exposure, despite the increased oxidative damage, led us to study another pro-oxidant factor, namely Low Molecular Weight 
iron (LMW) iron. In addition, alterations in iron homeostasis have been already involved in the toxicity of both $\mathrm{B}[\mathrm{a}] \mathrm{P}$ and ethanol in liver cells $(15,19)$. Thus, $\mathrm{LMW}$ iron (that is, iron species not contained in high-molecular-weight molecules, such as ferritin or mitochondrial ferroproteins), can trigger oxidative stress not only by catalyzing the formation of highly reactive hydroxyl radicals but also more directly by leading to the formation of the oxidant ferryl and perferryl species (31). Lipid peroxidation and the drop in cell viability were related to LMW iron since deferiprone (a known specific LMW iron chelator) inhibited these effects due to co-exposure as well as those due to toxicants alone (Figure 3A-C). Finally, whereas ethanol and $\mathrm{B}[\mathrm{a}] \mathrm{P}$ alone increased LMW iron pool, as measured by EPR, co-exposing hepatocytes to both molecules led to a further significant increase (Figure 3D), thereby corroborating the important role of iron in the co-exposure-induced oxidative stress and cell death.

\section{Role for lysosomal membrane permeabilization}

Our previous data regarding the toxicity of $\mathrm{B}[\mathrm{a}] \mathrm{P}$ or ethanol alone have clearly evidenced a role for lysosomes, notably through their important contribution to intracellular LMW iron content $(21,32)$. Indeed, LMW iron could be delivered to these organelles by autophagic degradation of ferroproteins, such as ferritin or mitochondrial electron transport complexes. Using electron microscopy, co-exposure appeared to induce an increase in number of vesicles with degraded mitochondria, when compared to toxicants alone (See Supplementary Material, Figure 2S). An increase in lysosomes was also observed. Bafilomycin, an inhibitor of the lysosomal pathway, blocked the cytotoxicity (Figures 4A and 4B), caspase activity (Figure 4C) and lipid peroxidation (Figure 4D) induced by $\mathrm{B}[\mathrm{a}] \mathrm{P} / \mathrm{ethanol}$ co-exposure. In addition, by using flow cytometry, an increase in permeabilization of lysosome membranes was evidenced upon co-exposure compared to toxicants alone, notably following a $5 \mathrm{~h}$ co- 
treatment (Figure 4E). Pepstatin A, an inhibitor of cathepsin D, protease likely to be released from permeabilized lysosomes, prevented the co-exposure toxicity as well as that of toxicants alone (Figures 4A and 4B). Interestingly, it was also able to inhibit caspase activity (Figure 4C). Once again, relationship between LMW iron, oxidative stress and lysosomes could be established, since deferiprone and vitamin $\mathrm{E}$ inhibited the lysosomal membrane permeabilization (LMP) induced by the co-exposure (See Supplementary Material, Figure $3 S)$.

\section{Key role of membrane remodeling}

Membrane remodeling, characterized by both an increase in fluidity and lipid raft alterations, is known to play a key role in the cell death induced by $\mathrm{B}[\mathrm{a}] \mathrm{P}(15-17)$ and ethanol alone (1921). A membrane stabilizer (UDCA) or a lipid raft disrupter (CHOX) inhibited the effect of co-exposure on cell viability (Figures 5A and 5B), lipid peroxidation (Figure 5C), LMW iron content (Figures 5D), and LMP (See Supplementary Material, Figure 2S). As we had demonstrated the involvement of LMW iron, oxidative stress and LMP in the toxicity of the co-exposure, these data therefore pointed to the key role of membrane remodeling in the toxic effects of co-exposure. The next set of experiments was carried out in order to gain further insight into the possible membrane remodeling upon co-exposure. Thus, co-exposure induced a further increase in bulk membrane fluidity compared to toxicants alone (Figure 6A), and lipid raft chemical alterations (Figures 6B and 6C). In addition, co-exposure decreased the raft cholesterol content compared to controls (Figure 6B); however no significant difference was observed relatively to $\mathrm{B}[\mathrm{a}] \mathrm{P}$ alone, suggesting the main role for $\mathrm{B}[\mathrm{a}] \mathrm{P}$ in this coexposure effect. Nonetheless, a significant further decrease in the activity of alkaline phosphatase was observed as compared to $\mathrm{B}[\mathrm{a}] \mathrm{P}$ or ethanol alone (Figure $6 \mathrm{C}$ ). Note that all treatments did not markedly change the flotillin-1 (a protein raft marker) distribution in 
membranes (Figure 6D). In addition, raft staining of the raft-associated GM1 glycosphingolipid showed that, as expected, ethanol alone led to raft aggregation (as evidenced by punctuated staining), whereas a raft destabilization was observed upon $\mathrm{B}[\mathrm{a}] \mathrm{P}$ treatment (as visualized by diffuse staining). Regarding $\mathrm{B}[\mathrm{a}] \mathrm{P} / \mathrm{ethanol}$ co-exposure, both types of alterations were observed, but at a lesser extent for raft aggregation (Figure 6E).

\section{Involvement of PLC $\gamma 1$ relocation to lipid rafts}

As we previously showed for ethanol alone that lipid raft clustering promotes PLC $\gamma 1$ relocation to lipid rafts, triggering its own activation and enhancing oxidative stress through lysosome alteration and increase in LMW iron (21), we decided to study the PLC 1 relocation in the context of the co-exposure. It is worth stressing that the activity of alkaline phosphatase, a glycosylphosphatidylinositol (GPI)-anchored enzyme known to be a target of PLC $\gamma 1$, was demonstrated to be decreased by the co-exposure when compared to toxicants alone (Figure 6E). As expected from our previous data concerning ethanol alone, merging of fluorescence staining led to the appearance of yellow patches indicating that GM1 and PLC $\gamma 1$ co-localized (Figure 7A). More interestingly, the co-exposure maintained this translocation even though lipid rafts were partially destabilized. Note that $\mathrm{B}[\mathrm{a}] \mathrm{P}$ alone was not able to induce this translocation. By western blotting, PLC $\gamma 1$ expression was found to slightly increase in lipid rafts when compared to ethanol alone, despite less raft aggregation (Figure 7B). In addition, NCDC, a specific PLC $\gamma 1$ inhibitor, protected from both toxicity (Figures 7C and 7D) and LMP (See Supplementary Material, Figure $\underline{3} S$ ). It is noteworthy that this inhibitor did not protect from B[a]P toxicity (Figures 7C and 7D), unlike ethanol toxicity.

As membrane remodeling has been shown to be a major actor in the co-exposure toxicity, we decided to study its involvement, more specifically the raft cholesterol depletion, in the co- 
exposure-increased PLC $\gamma 1$ relocation into lipid rafts. Thus, in $\mathrm{B}[\mathrm{a}] \mathrm{P} / \mathrm{ethanol-treated}$ hepatocytes, cholesterol supply protected from lipid raft destabilization and PLC $\gamma 1$ relocation (Figure 7E). Note that, in this set of experiments, confocal fluorescence microscopy was used explaining that raft destabilization appeared as weaker fluorescence of membranes instead of diffuse fluorescence as observed with conventional fluorescence microscopy (Figure 6E). In addition, in cells treated with ethanol alone, neither lipid raft clustering nor PLC $\gamma 1$ translocation into lipid rafts were altered whereas $\mathrm{B}[\mathrm{a}] \mathrm{P}$ alone-induced lipid raft destabilization was inhibited (Figure 7E). Therefore, relocation of PLC $\gamma 1$ to lipid rafts was dependent on cholesterol depletion only for the co-exposure. It is worth remembering that $\mathrm{B}[\mathrm{a}] \mathrm{P}$ plays the main role in the co-exposure induced cholesterol depletion. Finally, cholesterol protected from this toxicity and also from that of $\mathrm{B}[\mathrm{a}] \mathrm{P}$ alone, but was ineffective on ethanol toxicity (Figures 7C and 7D); such differential effects for the cholesterol supply were also observed when considering LMP (See Supplementary Material, Figure $\underline{3}$ S). 


\section{Discussion}

In this paper, for the first time, ethanol was shown to act reciprocally with $\mathrm{B}[\mathrm{a}] \mathrm{P}$ in promoting hepatocyte oxidative stress and cell death through a novel mechanism of interaction between both toxicants, never described before, that involved plasma membrane remodeling and lysosomal membrane permeabilization. Indeed, both toxicants differentially acted on plasma membrane to ultimately lead to an increase in membrane fluidity and lipid raft alterations. By using a membrane stabilizer or a lipid raft disrupter, these effects were shown to be implicated in oxidative stress and cell death. First, as previously shown $(16,19)$, both toxicants alone increased membrane fluidity, very likely through different mechanisms, which resulted in a larger membrane fluidization for the co-exposure. Second, they can also alter lipid rafts of the plasma membrane; these microdomains are detergent-resistant and rich in sphingolipids and cholesterol, which confer them a highly ordered spatial structure. The two toxicants opposingly altered lipid rafts, as previously reported $(17,20)$. Thus, whereas $\mathrm{B}[\mathrm{a}] \mathrm{P}$ modified raft organization by decreasing their cholesterol content, ethanol induced raft clustering; as a result, co-exposure triggered raft clustering but at a lesser extent. Previously, we $(20,21)$ and others (33) clearly demonstrated the involvement of lipid raft clustering in ROS production by activated various redox signaling pathways. Regarding ethanol, a phospholipase C-dependent pathway was described (20). Indeed, ethanol-induced lipid raft clustering was found to promote PLC $\gamma 1$ translocation and subsequent activation leading to oxidative stress in primary rat hepatocytes (20). Upon co-exposure, to ethanol-induced raft clustering was associated the $\mathrm{B}[\mathrm{a}] \mathrm{P}$ effect i.e. the drop in raft cholesterol content; compared to toxicants alone, this latter effect would ultimately enhance PLC $\gamma 1$ translocation into lipid rafts, thus explaining the increase in oxidative stress. Indeed, the decrease in raft cholesterol content, by fluidizing lipid rafts, may promote PLC $\gamma 1$ raft insertion ; regarding this point, it is noteworthy that PLC $\gamma 1$ activity has been shown to increase with membrane fluidization (34). 
Thus, cholesterol could appear as an attractive target since cholesterol supplementation was able to partially protect from cell death induced by $\mathrm{B}[\mathrm{a}] \mathrm{P}$ alone and $\mathrm{B}[\mathrm{a}] \mathrm{P} / \mathrm{ethanol}$ coexposure. Note that cholesterol increased ethanol alone toxicity likely by increasing raft clustering.

Previously, we showed that PLC $\gamma 1$ participated to ethanol-induced oxidative stress and cell death by promoting lysosome accumulation, a major source of a known pro-oxidant, the LMW iron (21). Indeed, lysosomes can accumulate large amounts of LMW iron by degradation of macromolecules containing iron such as ferritin and mitochondrial electron transport complexes (35). Compared to toxicants alone, $\mathrm{B}[\mathrm{a}] \mathrm{P} / \mathrm{ethanol}$ co-exposition was able to increase lysosome accumulation and LMW iron content, that could be linked to the elevation of PLC $\gamma 1$ activity. Once again, a new mechanism involving a toxic cooperation between both compounds leading to lysosomal membrane permeabilization could explain the enhancement of lipid peroxidation and cell death due to the co-exposure. Indeed, in primary rat hepatocytes, ethanol, but not $\mathrm{B}[\mathrm{a}] \mathrm{P}$, induced ROS production whereas both toxicants were found to participate to the elevation of LMW iron. Considering these differential effects on ROS production, one might propose the following scenario: in lysosomes, $\mathrm{H}_{2} \mathrm{O}_{2}$ provided by ethanol metabolism would allow the formation of hydroxyl radical by a reaction catalyzed by LMW iron, leading to lipid peroxidation of lysosome membranes (35). As both toxicants work together to increase the LMW iron pool, lipid peroxidation would then be enhanced, thereby further destabilizing lysosomal membranes (Figure 8). In support to this, we found an enhancement of LMP upon co-exposure compared to toxicants alone, and pretreatment with vitamin E, a lipid peroxidation inhibitor, was shown to protect from it. Such a similar oxidative process has been reported in hepatocytes stressed by cytokines (36), free fatty acids (37) or hyperthermia (38); however our study is the first one to show that such an interaction between both toxicants can induce LMP through plasma membrane remodeling. Considering 
this point, the depletion in membrane cholesterol due to $\mathrm{B}[\mathrm{a}] \mathrm{P}$ (previously reported to be due to inhibition of HMG CoA reductase, the first enzyme in cholesterol synthesis (17)), would also participate to lysosomal disruption. Indeed, recent studies described that cholesterol accumulation in lysosomes could protect from oxidant-induced LMP (39), whereas cholesterol depletion decreased lysosome stability (40). In our model, repletion in cholesterol protected from the co-exposure-induced LMP and cell death. In addition, a role for aryl hydrocarbon receptor $(\mathrm{AhR})$, a $\mathrm{B}[\mathrm{a}] \mathrm{P}$-activated transcription factor, in lysosomal disruption has also been established in hepatic epithelial cells (41). Although speculative, this could be linked to the cholesterol depletion since we (17) and others (42) demonstrated that AhR activation led to a decreased expression of several enzymes involved in cholesterol synthesis. Besides, it should also be noted that ethanol was reported to be able to activate AhR in mouse hepatic stellate cells (43). Taken altogether, our results showed that ethanol and $\mathrm{B}[\mathrm{a}] \mathrm{P}$ through mechanisms specific to each toxicant, i.e. cholesterol depletion for $\mathrm{B}[\mathrm{a}] \mathrm{P}$ and ROS production for ethanol, led to an important LMP. Accumulated evidence suggested that this process can lead to apoptotic or necrotic cell death by the translocation of lysosomal contents to the cytoplasm depending on the intensity of lysosome disruption $(35,44)$. In our model, after 5 hours of ethanol incubation, lysosome disruption remains moderate (+ $29 \%$ ) explaining that no necrosis could be detected.

Caspase activity appeared to be crucial in the apoptotic process since pan caspase inhibitor totally inhibited the increase in apoptotic cell number. Interestingly, the caspase activation appeared to rely upon the release of cathepsins by LMP. Many papers reported the ability of cathepsins to directly activate caspases, or indirectly by promoting mitochondrial outer membrane permeabilization (44-46). This latter possibility seems to be the most likely in the present study since the delay for the co-exposure to induce apoptosis increase ( 8 hours). Indeed, even though these tests are not the best, mitochondrial alteration analyzed by MTT 
test and ATP depletion was detected at 5 hours, that is before the occurrence of apoptosis; furthermore, pepstatin A, a cathepsin D inhibitor, protected from this mitochondrial damage suggesting the harmful effect of released cathepsin D on mitochondria.

Taken altogether, for the first time, it was demonstrated in this paper, that both toxicantinduced opposite effects on plasma membrane especially lipid rafts can finally interact to increase a toxic raft-dependent cell signaling pathway (phospholipase C-dependent), that, in addition, was not activated by one of the toxicants alone (namely $\mathrm{B}[\mathrm{a}] \mathrm{P}$ ). Consequences of this plasma membrane interaction are important since several cytoprotective compounds (NCDC or cholesterol) identified for each toxicant alone could be used to target the coexposure toxicity, with a complete afforded protection, whereas they were ineffective for one or the other toxicants when applied alone. In conclusion, exposure to $\mathrm{B}[\mathrm{a}] \mathrm{P}$, by depleting cholesterol membrane content of hepatocytes, would constitute a favorable ground for a later toxic aggression such as ethanol intoxication. By a cooperative remodeling of plasma membrane leading to lysosome accumulation (Figure 8), B[a]P and ethanol would act together to trigger lysosomal membrane permeabilization, cathepsin release and caspase activation. In this context, membrane stabilization of both plasma membrane and lysosomes might be a potential target for further investigation considering cytoprotective strategies. 


\section{Acknowledgements}

We thank the microscopy platform MRic (Microscopy Rennes Imaging Center, SFR Biosit, Rennes, France) for immunofluorescence analysis and Marie-Thérèse Lavault for her technical assistance in TEM experiments. We also thank animal house platform ARCHE (SFR Biosit, Rennes, France) and Laurence Bernard-Touami for her assistance. European union (FEDER), the Region Bretagne, the Conseil Général d'Ille-et-Vilaine, Rennes Métropole and the French Ministry of High Education and Research (MESR) are also thanked for the financial support of the project Membratox (Contract number 32508, 350 keuros). This study was financially supported by the Ligue Régionale Grand-Ouest contre le Cancer (committees 22, 35, 85). Aurore Collin was a recipient of a fellowship from the Ligue Nationale contre le Cancer, and Kévin Hardonnière a recipient of a fellowship from the French Ministry of High Education and Research.

\section{List of Abbreviations :}

$\mathrm{B}[\mathrm{a}] \mathrm{P}$, benzo[a]pyrene ; CHOX, cholesterol oxidase ; 12-DSA, 12-doxylstearic acid ; EPR, electron paramagnetic resonance ; GM1, monosialotetrahexosyl ganglioside ; HMG CoA reductase, hydroxymethylglutaryl-CoA reductase; LDH, lactate dehydrogenase ; LMP, lysosomal membrane permeabilization ; LMW iron, low-molecular-weight iron ; MTT, thiazolyl blue tetrazolium blue; NCDC, 2-nitro-4-carboxyphenyl- $N, N$-diphenylcarbamate ; PAH, polycyclic aromatic hydrocarbon ; PI-PLC, phosphatidylinositol-specific phospholipase C ; ROS, reactive oxygen species ; TEM, transmission electron microscopy ; UDCA, ursodeoxycholate sodium salt ; $\underline{\mathrm{Z}-\mathrm{VAD}}$, $\underline{\mathrm{N}-\text { Benzyloxycarbonyl-Val-Ala-Asp(O-Me) }}$ fluoromethyl ketone. 


\section{References}

1. IARC. Some non-heterocyclic polycyclic aromatic hydrocarbons and some related exposures. Monogr. Eval. Carcinog. Risks Hum. 92:1-853; 2010.

2. Pelkonen, O.; Nebert, D.W. 1982. Metabolism of polycyclic aromatic hydrocarbons : etiologic roles in carcinogenesis. Pharmacol. Rev. 34:189-222; 1982.

3. Miller, K.P.; Ramos, K.S. Impact of cellular metabolism on the biological effects of benzo[a]pyrene and related hydrocarbons. Drug Metab. Rev. 33:1-35; 2001.

4. Lee, Y.C.A; Cohet, C.; Yang, Y.C.; Stayner, L.; Hashibe, M.; Straif, K. Meta-analysis of epidemiologic studies on cigarette smoking and liver cancer. Int. J. Epidemiol. 38:1487-1511; 2009.

5. Chen, S.Y.; Wang, L.Y.; Lunn, R.M.; Tsai, W.Y.; Lee, P.H.; Lee, C.S.; Ahsan, H.; Zhang, Y.J.; Chen, C.J.; Santella, R.M. Polycyclic aromatic hydrocarbon-DNA adducts in liver tissues of hepatocellular carcinoma patients and controls. Int. J. Cancer 99:14-21; 2002.

6. Rubin, H. 2001. Synergistic mechanisms in carcinogenesis by polycyclic aromatic hydrocarbons and by tobacco smoke : a bio-historical perspective with updates. Carcinogenesis 22:1903-1930; 2001.

7. Shiizaki, K.; Kawanishi, M.; Yagi, T. Dioxin suppresses benz[a]pyrene-induced mutations and DNA adduct formation through cytochrome P450 1A1 induction and ( \pm )-antibenzo[a]pyrene-7,8-diol-9,10-epoxide inactivation in human hepatoma cells. Mut. Res. 750:77-85; 2013.

8. Delgado, M.E.; Haza, A.I.; Arranz, N.; Garcia, A.; Morales, P. Dietary polyphenols protect against N-nitrosamines and benzo(a)pyrene-induced DNA damage (strand breaks and oxidized purine/pyrimidines) in HepG2 human hepatoma cells. Eur. J. Nutr. 47:479-490; 2008 .

9. Huc, L.; Rissel, M.; Solhaug, A.; Tekpli, X.; Gorria, M.; Torriglia, A.; Holme, J.A.; 
Dimanche-Boitrel, M.T., Lagadic-Gossmann, D. Multiple apoptotic pathways induced by p53-dependent acidification in benzo[a]pyrene-exposed hepatic F258 cells. J. Cell. Physiol. 2083:527-37; 2006.

10. Solhaug, A.; Refsnes, M.; Holme, J.A. Role of cell signaling involved in induction of apoptosis by benzo[a]pyrene and cyclopenta[c,d]pyrene in Hepa1C1C7 cells. J. Cell. Biochem. 93:1143-1154; 2004.

11. Weber, A.; Boger, R.; Vick, B.; Urbanik, T.; Haybaeck, J.; Zoller, S.; Teufel, A.; Krammer, P.H.; Opferman, J.T.; Galle, P.R.; Schuchmann, M.; Heikenwalder, M.; SchulzeBergkamen, H. Hepatocyte-specific deletion of the antiapoptotic protein myeloid cell leukemia-1 triggers proliferation and hepatocarcinogenesis in mice. Hepatology 51:1226$1236 ; 2010$.

12. Qiu, W.; Wang, X.; Leibowitz, B.; Yang, W.; Zhang, L.; Yu, J. PUMA-mediated apopotosis drives chemical hepatocarcinogenesis in mice. Hepatology 54:1249-1258; 2011.

13. Feng G.S. Conflicting roles of molecules in hepatocarcinogenesis : paradigm or paradox. Cancer Cell. 21:150-154; 2012.

14. Huc, L; Sparfel, L; Rissel, M; Dimanche-Boitrel, MT; Guillouzo, A; Fardel, O; LagadicGossmann, D. Identification of $\mathrm{Na}+/ \mathrm{H}+$ exchange as a new target for toxic polycyclic aromatic hydrocarbons. Faseb J. 287:C844-850; 2004.

15. Gorria, M.; Huc, L.; Sergent, O.; Rebillard, A.; Gaboriau, F.; Dimanche-Boitrel, M.T; Lagadic-Gossmann D. Protective effect of monosialoganglioside GM1 against chemically induced apoptosis through targeting of mitochondrial function and iron transport. Biochem. Pharmacol. 72:1343-1353; 2006.

16. Gorria, M.; Tekpli, X.; Sergent, O.; Huc, L.; Gaboriau, F.; Rissel, M.; Chevanne, M.; Dimanche-Boitrel, M.T.; Lagadic-Gossmann, D. Membrane fluidity changes are associated with benzo[a]pyrene-induced apoptosis in F258 cells : protection by exogenous cholesterol. 
Ann. N. Y. Acad. Sci. 1090:108-112; 2006.

17. Tekpli, X.; Rissel, M.; Huc, L.; Catheline, D.; Sergent, O.; Rioux, V.; Legrand, P.; Holme, J.A.; Dimanche-Boitrel, M.T.; Lagadic-Gossmann, D. Membrane remodeling, an early event in benzo[a]pyrene-induced apoptosis. Toxicol. Appl. Pharmacol. 243:68-76; 2010.

18. Tekpli, X.; Huc, L.; Sergent, O.; Dendelé, B.; Dimanche-Boitrel, M.T.; Holme, J.A.; Lagadic-Gossmann, G. NHE-1 relocation outside cholesterol-rich membrane microdomains is associated with its benzo[a]pyrene-related apoptotic function. Cell. Physiol. Biochem. 29:657-666; 2012.

19. Sergent, O.; Pereira, M.; Belhomme, C.; Chevanne, M.; Huc, L.; Lagadic-Gossmann, D. Role for membrane fluidity in ethanol-induced oxidative stress of primary rat hepatocytes. $J$. Pharmacol. Exp. Ther. 313:104-111; 2005.

20. Nourissat, P.; Travert, M.; Chevanne, M.; Tekpli, X.; Rebillard, A.; Le Moigne-Muller, G.; Rissel, M.; Cillard, J.; Dimanche-Boitrel, M.T.; Lagadic-Gossmann, D.; Sergent, O. Ethanol induces oxidative stress in primary rat hepatocytes through the early involvement of lipid raft clustering. Hepatology 47:59-70; 2008.

21. Aliche-Djoudi, F.; Podechard, N.; Chevanne, M.; Nourissat, P.; Catheline, D.; Legrand, P.; Dimanche-Boitrel, M.T.; Lagadic-Gossmann, D.; Sergent, O. Physical and chemical modulation of lipid rafts by a dietary n-3 polyunsaturated fatty acid increases ethanol-induced oxidative stress. Free Radic. Biol. Med. 51:2018- 2030; 2011.

22. Kuper, H.; Tzonou, A.; Kaklamani, E.; Hsieh, C.C.; Lagiou, P.; Adami, H.O.; Trichopoulos, D.; Stuver, S.O. Tobacco smoking, alcohol consumption and their interaction in the causation of hepatocellular carcinoma. Int. J. Cancer 85:498-502; 2000.

23. Shih, W.L.; Chang, H.C.; Liaw, S.M.; Lee, S.D.; Chen, P.J.; Liu, C.J.; Lin, C.L.; Yu, M.W. Influences of tobacco and alcohol use on hepatocellular carcinoma survival. Int. J. 
Cancer 131:2612-2621; 2012.

24. Purohit V.; Rapaka R.; Kwon O.S.; Song B.J. Roles of alcohol and tobacco exposure in the development of hepatocellular carcinoma. Life Sci. 92:3-9; 2013.

25. Guguen-Guillouzo, C.; Clement, B.; Baffet, G.; Beaumont, C.; Morel-Chany, E.; Glaise, D.; Guillouzo A. Maintenance and reversibility of active albumin secretion by adult rat hepatocytes co-cultured with another liver epithelial cell type. Exp. Cell. Res. 143:47-54; 1983.

26. Holme, J.A.; Gorria, M.; Arlt, V.M.; Ovrebø, S.; Solhaug, A.; Tekpli, X.; Landvik, N.E.; Huc, L.; Fardel, O.; Lagadic-Gossmann, D. Different mechanisms involved in apoptosis following exposure to benzo[a]pyrene in F258 and Hepa1c1c7 cells. Chem. Biol. Interact. 167:41-55; 2007.

27. Gilot, D.; Loyer, P.; Corlu, A.; Glaise, D.; Lagadic-Gossmann, D.; Atfi, A.; Morel, F.; Ichijo, H., Guguen-Guillouzo, C. Liver protection from apoptosis requires both blockage of initiator caspase activities and inhibition of ASK1/JNK pathway via glutathione S-transferase regulation. J. Biol. Chem. 277:49220-49229; 2002.

28. Gomes, A.; Fernandes, E.; Lima, J.L.F.C. Fluorescence probes used for detection of reactive oxygen species. J. Biochem. Biophys. Method. 65:45-80; 2005.

29. Sergent, O.; Anger, J.-P.; Lescoat, G.; Pasdeloup, N.; Cillard, P.; Cillard, J. EPR determination of low molecular weight iron content applied to whole rat hepatocytes. Cell. Mol. Biol. (Noisy-le-grand) 43:793-800; 1997.

30. Antras-Ferry, J.; Mahéo, K.; Morel, F.; Guillouzo, A., Cillard, P.; Cillard, J. Dexamethasone differently modulates TNF- $\alpha$ - and IL1 $\beta$-induced transcription of the hepatic Mn-superoxide dismutase gene. FEBS Letters 403:100-104; 1997.

31. Ryan, T.P.; Aust, S.D. The role of iron in oxygen mediated toxicities. Crit. Rev. Toxicol. 22:119-141; 1992. 
32. Gorria, M.; Tekpli, X.; Rissel, M.; Sergent, O.; Huc, L.; Landvik, N.; Fardel, O.; Dimanche-Boitrel, M.T.; Holme, J.A.; Lagadic-Gossmann, D. A new lactoferrin- and irondependent lysosomal death pathway is induced by benzo[a]pyrene in hepatic epithelial cells. Toxicol. Appl. Pharmacol. 2282:212-24; 2008.

33. Jin, S.; Zhou, F.; Katirai, F.; Li; P.L. Lipid raft redox signaling : molecular mechanisms in health and disease. Antioxid. Redox Signal. 15:1043-1083; 2011.

34. Lehto, M.T.; Sharom, F.J. PI-specific phospholipase C cleavage of a reconstituted GPIanchored protein : modulation by the lipid bilayer. Biochemistry 41:1398-1408; 2002.

35. Terman A.; Kurz, T. Lysosomal iron, iron chelation, and cell death. Antioxid. Redox Signal. 18:888-898; 2013.

36. Autelli, R; Crepaldi, S.; De Stefanis, D.; Parola, M.; Bonelli, G.; Baccino, F.M. Intracellular free iron and acidic pathways mediate TNF-induced death of rat hepatoma cells. Apoptosis 10:777-786; 2005.

37. Feldstein, A.E.; Werneburg, N.W.; Li, Z.Z.; Bronk, S.F.; Gores, G.J. Bax inhibition protects against free fatty acid-induced lysosomal permeabilization. Am. J. Physiol. Gastrointest. Liver Physiol. 290:G1339-G1346; 2006.

38. Arthur, P.G.; Niu, X.; Rigby, P.; Steer, J.H.; Jeffrey, G.P. Oxidative stress causes a decline in lysosomal integrity during hypothermic incubation of rat hepatocytes. Free Radic. Biol. Med. 44:24-33; 2008.

39. Reiners, J.J.; Kleinman, M.; Kessel, D.; Mathieu, P.A.; Caruso, J.A. Nonesterified cholesterol content of lysosomes modulates susceptibility to oxidant-induced permeabilization. Free Radic. Biol. Med. 50:281-294; 2011.

40. Appelqvist, H.; Sandin, L.; Björnström, K.; Saftig, P.; Garner, B.; Öllinger, K.; Katarina Kågedal, K. Sensitivity to lysosome-dependent cell death is directly regulated by lysosomal 
cholesterol content. Plos one 7, e50262; doi: 10.1371/journal.pone.0050262. [Online 16 November 2012].

41. Caruso, J.A.; Mathieu, P.A.; Joiakim, A.; Zhang, H.; Reiners, J.J. Aryl hydrocarbon receptor modulation of tumor necrosis factor-alpha-induced apoptosis and lysosomal disruption in a hepatoma model that is caspase-8-independent. J. Biol. Chem. 281:10954-67; 2006.

42. Tanos, R.; Patel, R.D.; Murray, I.A.; Smith, P.B.; Patterson, A.D.; Perdew, G.H. Aryl hydrocarbon receptor regulates the cholesterol biosynthetic pathway in a dioxin response element-independent manner. Hepatology 55:1994-2004; 2012.

43. Zhang, H.F.; Lin, X.H.; Yang, H.; Zhou, L.C.; Guo, Y.L.; Barnett, J.V.; Guo, Z.M. Regulation of the activity and expression of aryl hydrocarbon receptor by ethanol in mouse hepatic stellate cells. Alcohol. Clin. Exp. Res. 36:1873-1881; 2012.

44. Boya, P.; Kroemer, G. Lysosomal membrane permeabilization in cell death. Oncogene 27:6434-6451; 2008.

45. Conus, S.; Simon, H.-U. Cathepsins ; key modulators of cell death and inflammatory responses. Biochem. Pharmacol. 76:1374-1382; 2008.

46. Repnik, U.; Turk, B. Lysosomal-mitochondrial cross-talk during cell death. Mitochondrion 10:662-669; 2010. 
Figure legends
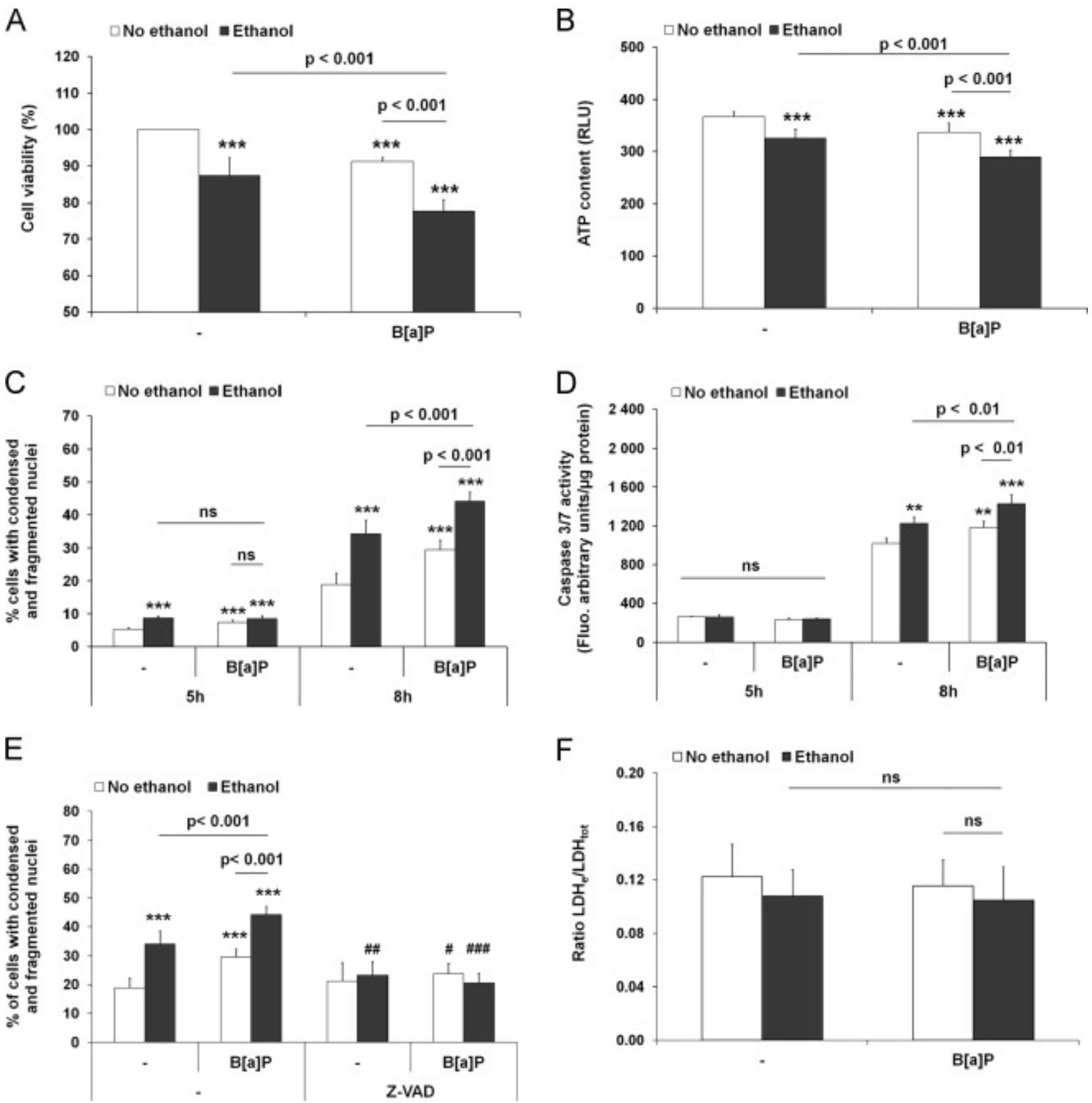

Figure 1. Ethanol increased benzo[a]pyrene (B[a]P) cytotoxicity through an elevation of apoptotic cell death. Metabolically active viable hepatocytes were determined both by (A) the mitochondrial succinate dehydrogenase activity using a MTT assay and by (B) the ATP content using a luminescent assay. Apoptosis was evaluated by (C) staining nuclear chromatin condensation with Hoechst 33342 (D) analysing DEVDase activities of caspase $3 / 7$ by spectrofluorimetry and (E) the effect of a pan caspase inhibitor (Z-VAD) on the 
number of cells with condensed and fragmented nuclei. (F) Necrosis was estimated by calculating the ratio of LDHe (extracellular lactate dehydrogenase) over LDHtot (total LDH $=\mathrm{LDHe}+$ intracellular LDH). Primary rat hepatocytes were treated or not for 18 hours with $100 \mathrm{nM} \mathrm{B}[\mathrm{a}] \mathrm{P}$ before $50 \mathrm{mM}$ ethanol addition (or not) for a further 5- or 8-hours incubation time. Some cultures were pretreated, for one hour, with $10 \mu \mathrm{M} Z \mathrm{ZVAD}$, a pan caspase inhibitor. In this case, ethanol was added for 8 hours._Values are given as means \pm standard deviation of at least seven independent experiments. Toxicant treated versus untreated cultures: ${ }^{*} \mathrm{p}<0.05 ;{ }^{* *} \mathrm{p}<0.01 ;{ }^{* * *} \mathrm{p}<0.001$. Z-VAD pretreated versus unpretreated cultures : $\# \mathrm{p}<0.05 ; \# \# \mathrm{p}<0.01 ; \# \# \mathrm{p}<0.001$.
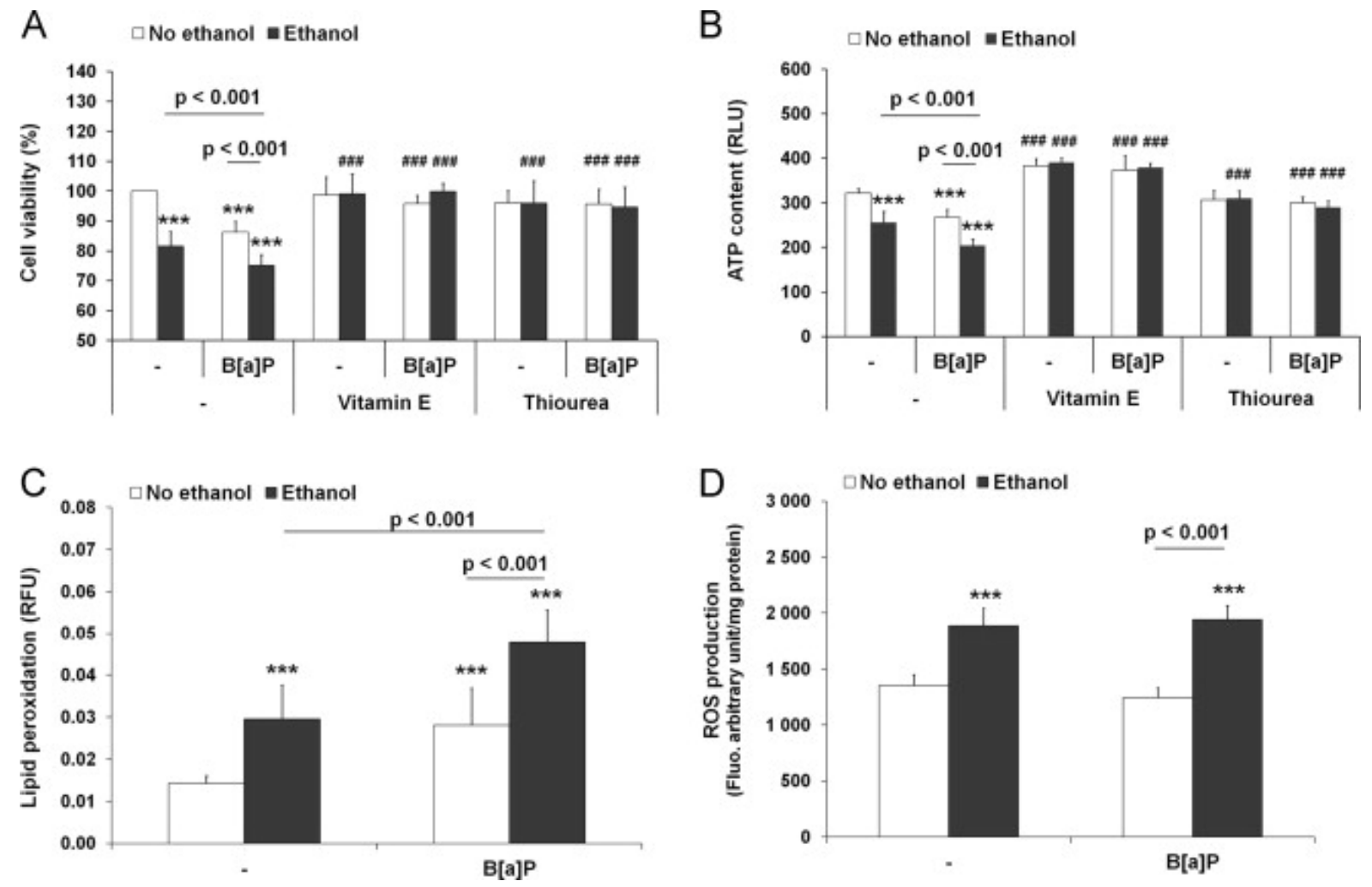

Figure 2. The increase by ethanol of benzo(a)pyrene (B[a]P) cytotoxicity could be related to oxidative stress. Metabolically active viable hepatocytes were evaluated both by (A) the mitochondrial succinate dehydrogenase activity using a MTT assay and by (B) the ATP content using a luminescent assay. (C) The increase in lipid peroxidation was measured by the relative fluorescence of the probe $\mathrm{C}_{11}$-Bodipy ${ }^{581 / 591}$. (D) ROS production was 
followed by the fluorescence of fluorescein. Primary rat hepatocytes were treated or not for 18 hours with $100 \mathrm{nM} \mathrm{B}$ [a]P before $50 \mathrm{mM}$ ethanol addition (or not) for a further 5-hours incubation time. Some cultures were pretreated, for one hour, with $100 \mathrm{mM}$ thiourea, a reactive oxygen species scavenger, or with $250 \mu \mathrm{M}$ vitamin $\mathrm{E}$, a free radical chain-breaking antioxidant. Values are given as means \pm standard deviation of at least five independent experiments. Toxicant treated versus untreated cultures: $* * * p<0.001$. Vitamin E or thiourea pretreated versus unpretreated cultures : \#p $<0.05$; \#\# $\mathrm{p}<0.01$; \#\# $<0.001$.
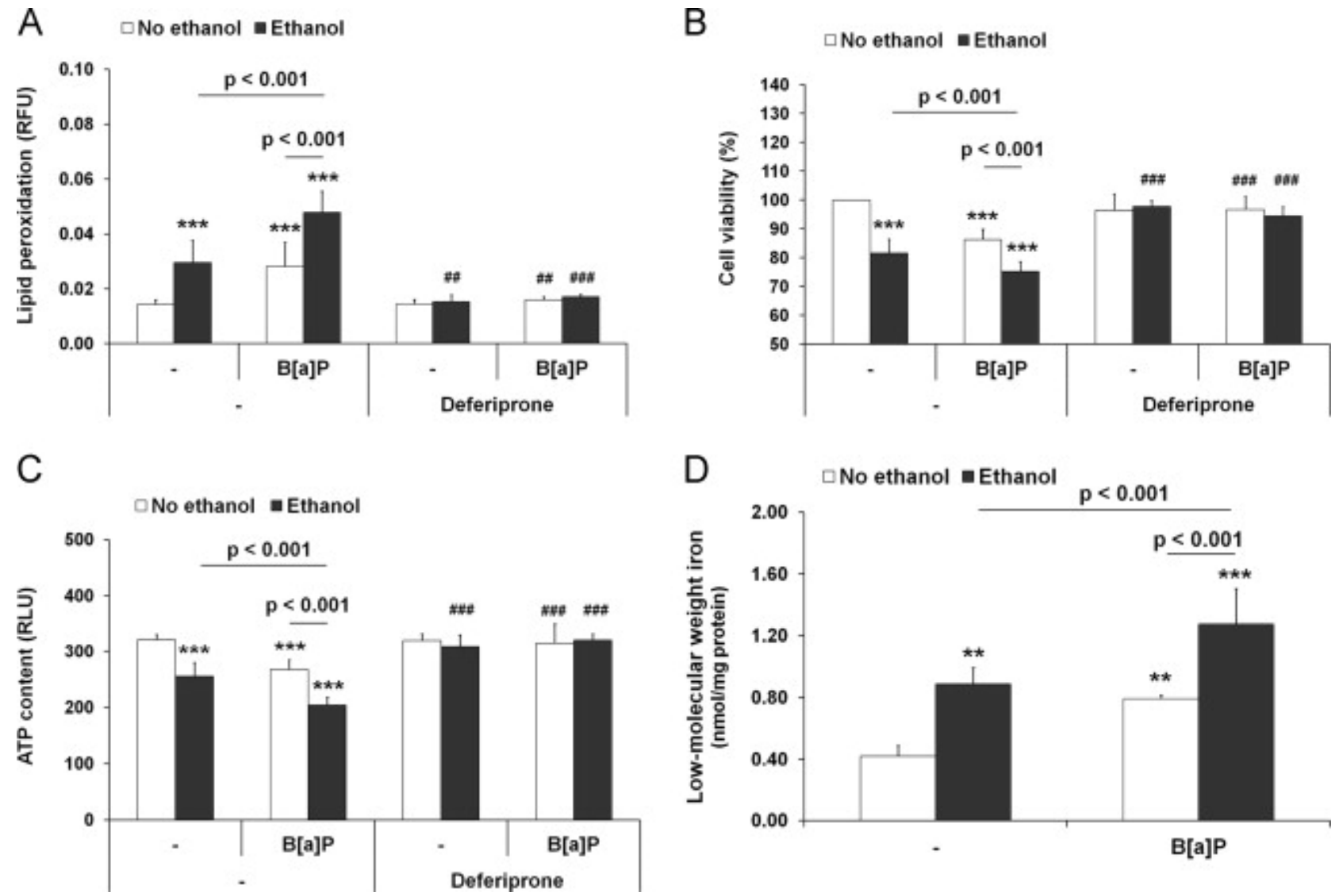

Figure 3. Involvement of LMW iron in the B[a]P/ethanol co-exposure cytotoxicity and oxidative stress. (A) Lipid peroxidation was measured by the relative fluorescence of the probe $\mathrm{C}_{11}$-Bodipy ${ }^{581 / 591}$. Metabolically active viable hepatocytes were evaluated both by (B) the mitochondrial succinate dehydrogenase activity using a MTT assay and by (C) the ATP content using a luminescent assay. (D) Intracellular low-molecular-weight (LMW) iron content was determined by electron paramagnetic resonance analysis after chelation by $3 \mathrm{mM}$ 
deferiprone. Primary rat hepatocytes were treated or not for 18 hours with $100 \mathrm{nM} \mathrm{B}[\mathrm{a}] \mathrm{P}$ before $50 \mathrm{mM}$ ethanol addition (or not) for a further 5-hours incubation time. Some cultures were pretreated with $30 \mu \mathrm{M}$ deferiprone, a LMW iron chelator, for one hour. Values are given as means $\pm \mathrm{SD}$ of at least three independent experiments. Toxicant treated versus untreated cultures: ** $\mathrm{p}<0.01 ; * * * \mathrm{p}<0.001$. Deferiprone pretreated versus unpretreated cultures : $\# \mathrm{p}<0.05 ; \# \# \mathrm{p}<0.01 ; \# \# \# \mathrm{p}<0.001$.

A
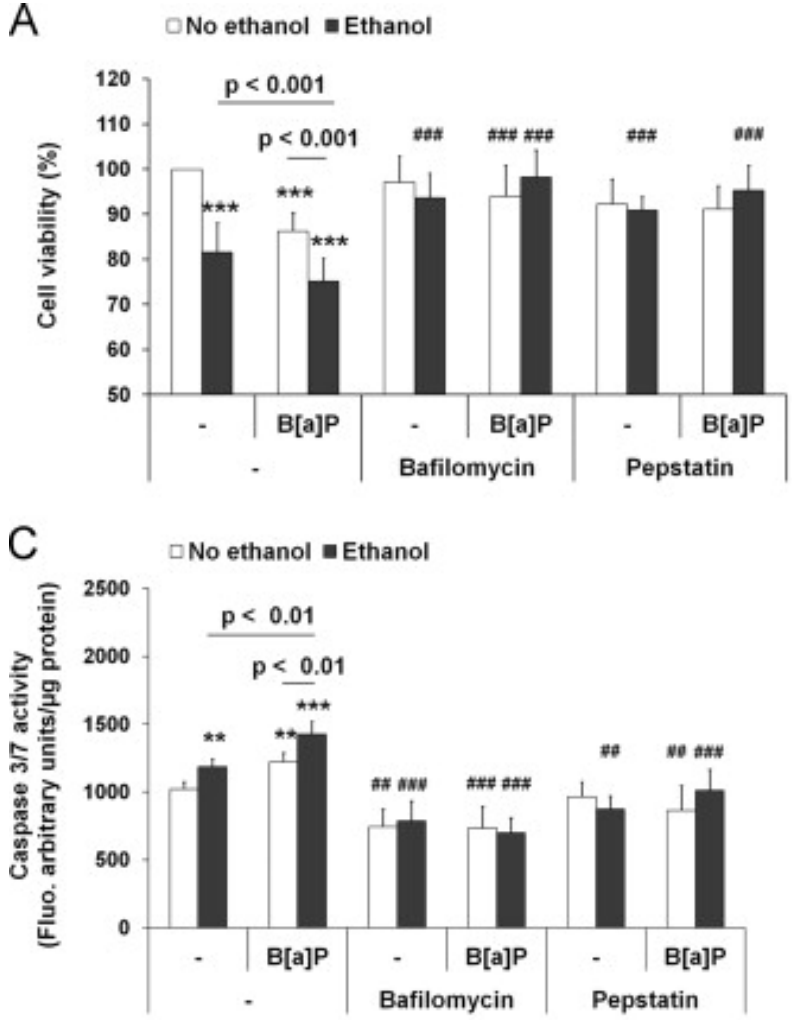

$E$

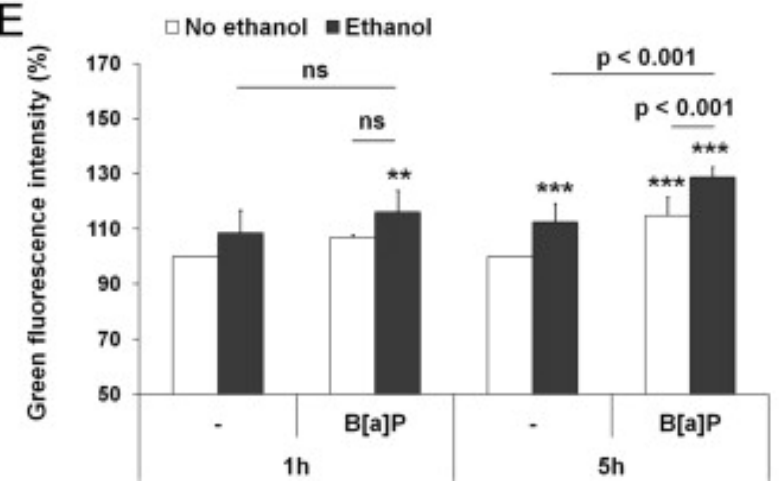

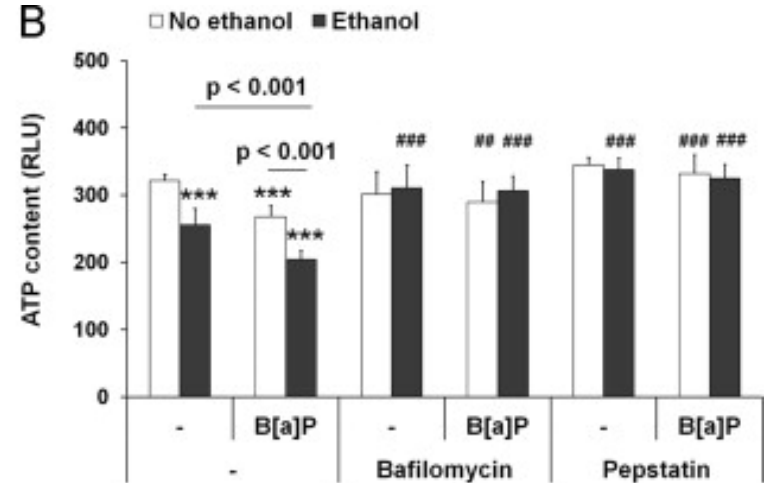

D No ethanol $=$ Ethanol

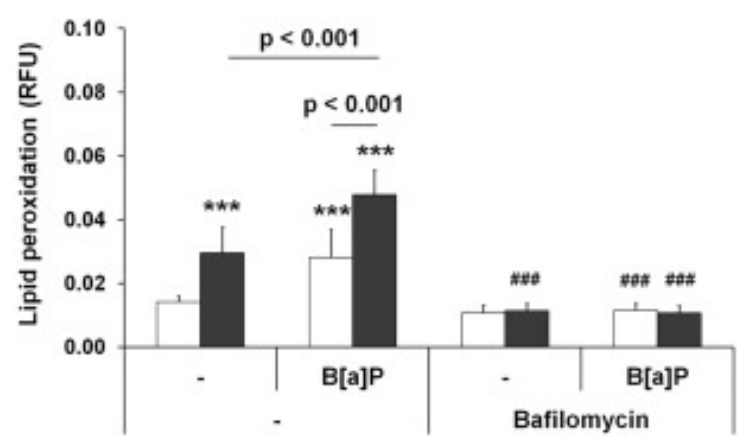

Figure 4. Involvement of lysosomes in the B[a]P/ethanol co-exposure cytotoxicity and oxidative stress. Metabolically active viable hepatocytes were evaluated both by (A) the 
mitochondrial succinate dehydrogenase activity using a MTT assay and by (B) the ATP content using a luminescent assay. (C) DEVDase activities of caspase 3/7 were analyzed by spectrofluorimetry. (D) Lipid peroxidation was measured by the relative fluorescence of the probe $\mathrm{C}_{11}$-Bodipy ${ }^{581 / 591}$. (E) Lysosomal membrane permeabilization was analyzed by flow cytometry using the green fluorescence of acridine orange. Primary rat hepatocytes were treated or not for 18 hours with $100 \mathrm{nM} \mathrm{B}$ [a]P before $50 \mathrm{mM}$ ethanol addition (or not) for a further 5-hours incubation time, except for caspase activity measurement for which ethanol was added for 8 hours. Some cultures were pretreated with $1 \mathrm{nM}$ bafilomycin or $15 \mu \mathrm{M}$ pepstatin A for one hour. Values are given as means \pm standard deviation of at least three independent experiments except for bafilomycin experiments for which $n \geq 4$. Toxicant treated versus untreated cultures: ${ }^{*} \mathrm{p}<0.05 ; * * \mathrm{p}<0.01 ; * * * \mathrm{p}<0.001$. Bafilomycin or pepstatin pretreated versus unpretreated cultures : \#p $<0.05$; \#\# $<<0.01 ; \# \# \# \mathrm{p}<0.001$.
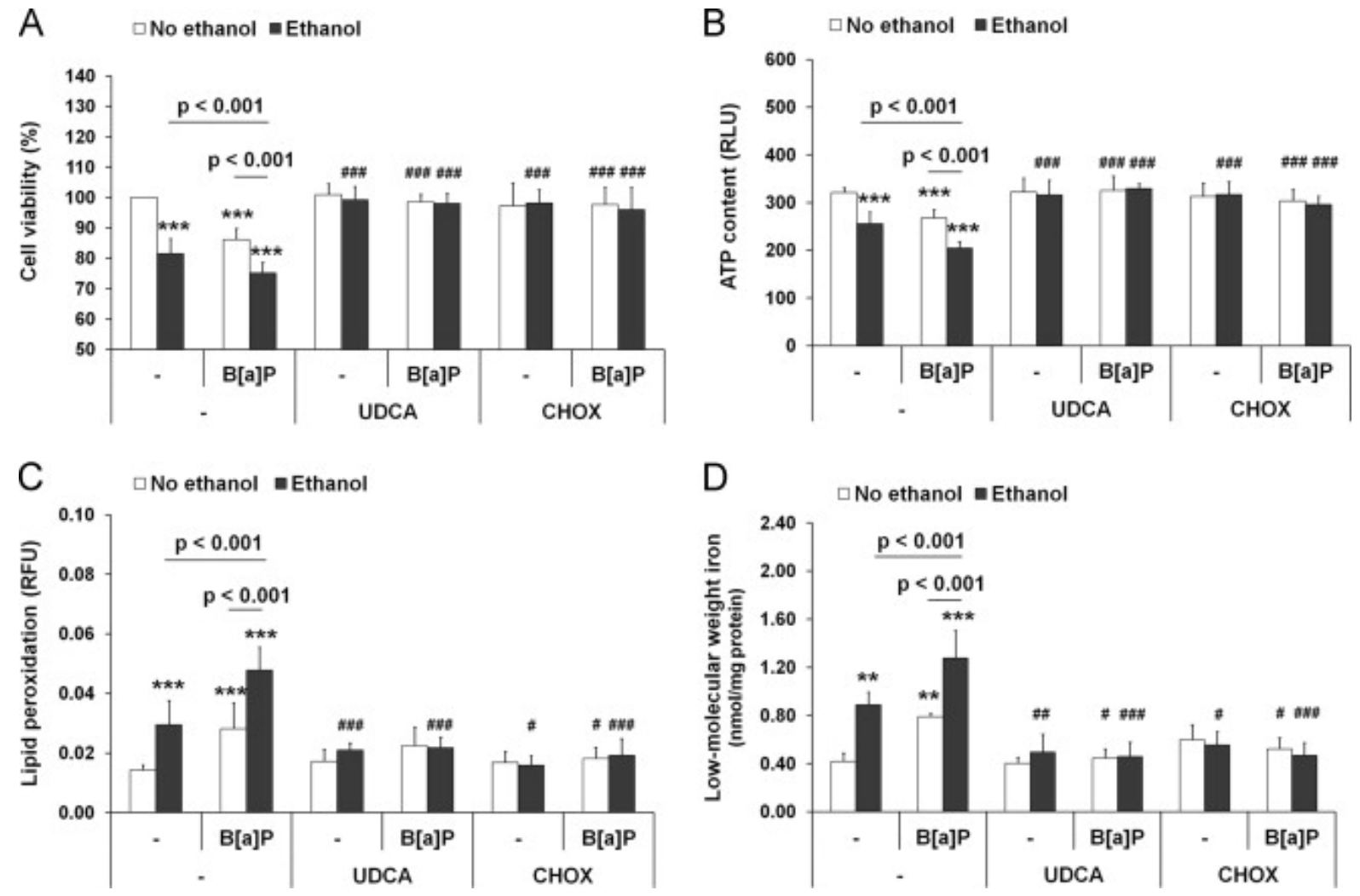

Figure 5. Membrane remodeling, characterized as membrane fluidization or lipid raft alteration, was involved in the $\mathrm{B}[\mathrm{a}] \mathrm{P} / \mathrm{ethanol}$ co-exposure cytotoxicity and oxidative 
stress. Metabolically active viable hepatocytes were evaluated both by (A) the mitochondrial succinate dehydrogenase activity using a MTT assay and by (B) the ATP content using a luminescent assay. (C) Lipid peroxidation was measured by the relative fluorescence of the probe $\mathrm{C}_{11}$-Bodipy ${ }^{581 / 591}$. (D) Intracellular low-molecular-weight iron content was determined by electron paramagnetic resonance analysis after chelation by $3 \mathrm{mM}$ deferiprone. Primary rat hepatocytes were treated or not for 18 hours with $100 \mathrm{nM} \mathrm{B}(\mathrm{a}) \mathrm{P}$ before $50 \mathrm{mM}$ ethanol addition (or not) for a further 5-hours incubation time. Some cultures were pretreated for one hour with $100 \mu \mathrm{M}$ ursodeoxycholic acid (UDCA), a membrane stabilizer, or with $0.05 \mathrm{U} / \mathrm{ml}$ cholesterol oxidase (CHOX), a lipid raft disruptor. Values are given as means \pm standard deviation of at least four independent experiments. Toxicant treated versus untreated cultures: $* * \mathrm{p}<0.01 ; * * * \mathrm{p}<0.001$. UDCA or CHOX pretreated versus unpretreated cultures : $\# \mathrm{p}<0.05$ ; \#\# $\mathrm{p}<0.01 ; \# \# \# \mathrm{p}<0.001$. 
A
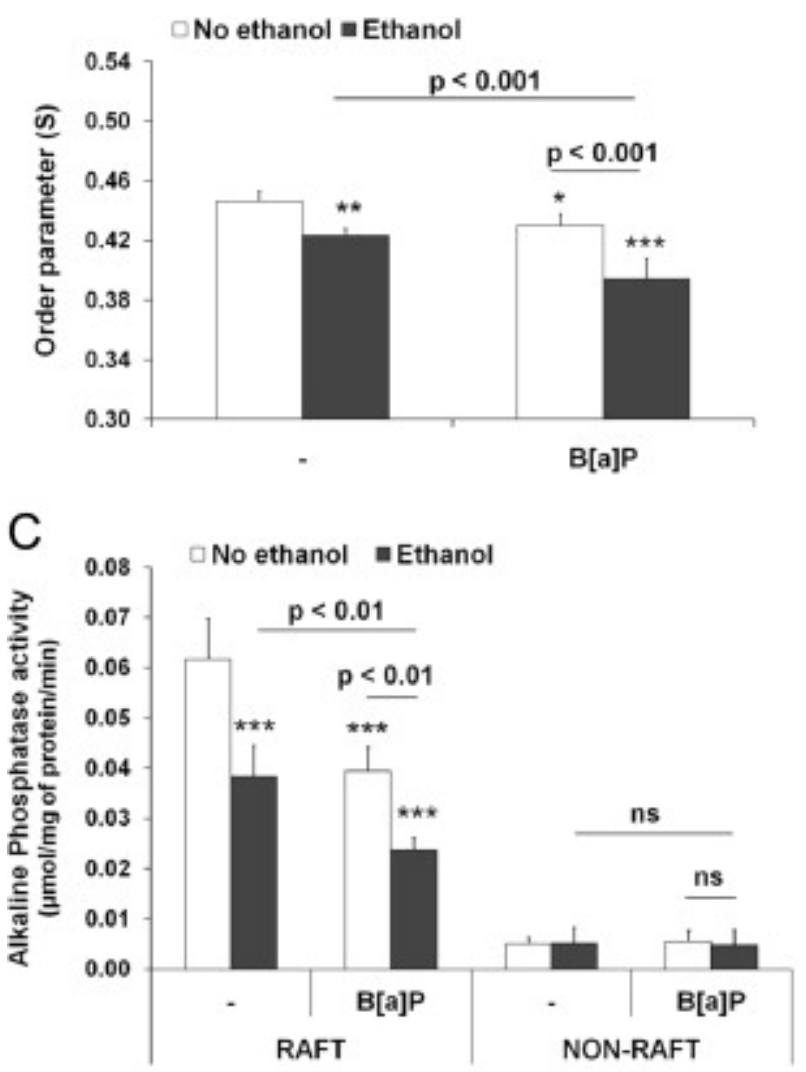

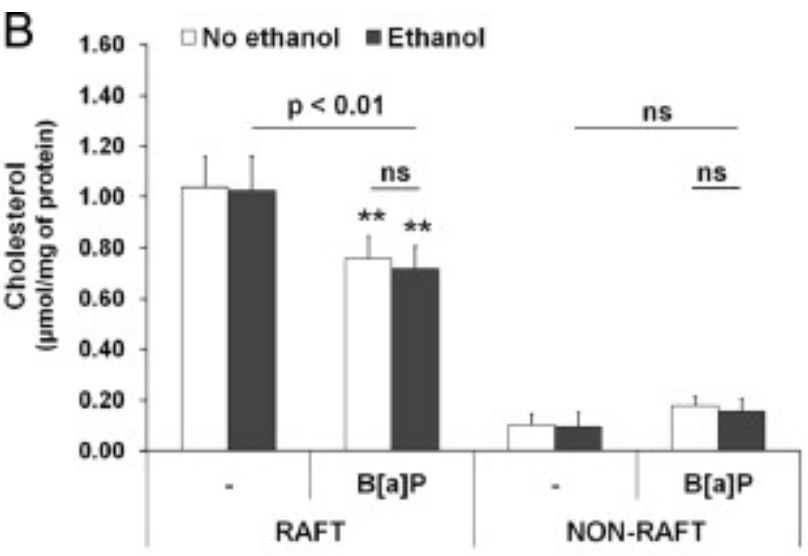

D

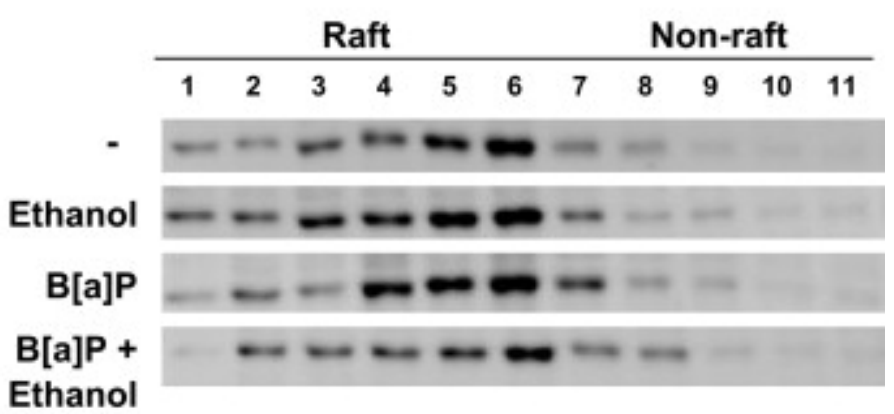

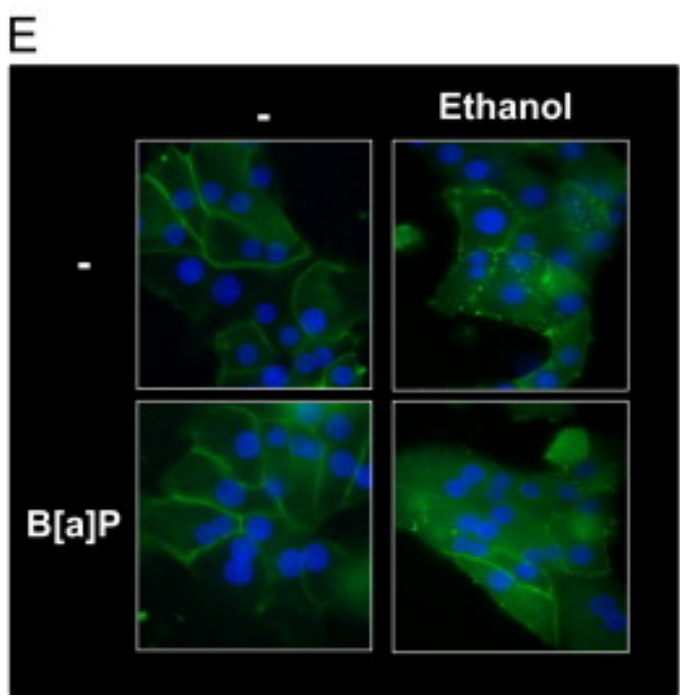

Figure 6. Ethanol modified the B[a]P-induced membrane remodeling, depicted by an enhancement of membrane fluidity and new physicochemical alterations of lipid rafts.

(A) The membrane fluidity was monitored by electron paramagnetic analysis of 12 doxylstearic acid embedded in membranes. This analysis resulted in the calculation of the order parameter which is inversely related to membrane fluidity. (B) Total amounts of 
cholesterol and (C) alkaline phosphatase activities were determined in pooled fractions 1-6 (detergent-resistant raft fractions) and 7-11 (soluble non raft fractions). Lipid rafts were obtained after lysis of hepatocytes in ice-cold 1\% Triton X-100 and fractionation on a sucrose density gradient by ultracentrifugation. (D) Flotillin-1 (protein raft marker) expression. An equal protein amount of each fraction was submitted to western blotting for analysis of flotillin-1. One representative of three independent experiments is shown. (E) Visualization of lipid rafts by conventional fluorescence microscopy using choleratoxin subunit B conjugated with Alexa Fluor 488 which binds the raft-associated glycosphingolipid GM1. One representative of three independent experiments is shown. Primary rat hepatocytes were treated or not for 18 hours with $100 \mathrm{nM} \mathrm{B}$ [a]P before $50 \mathrm{mM}$ ethanol addition (or not) for a further 5-hours incubation time. Values are given as means $\pm \mathrm{SD}$ of at least three independent experiments. Toxicant treated versus untreated cultures : ${ }^{*} \mathrm{p}<0.05 ;{ }^{* *} \mathrm{p}<0.01 ; * * * \mathrm{p}<0.001$. 
A

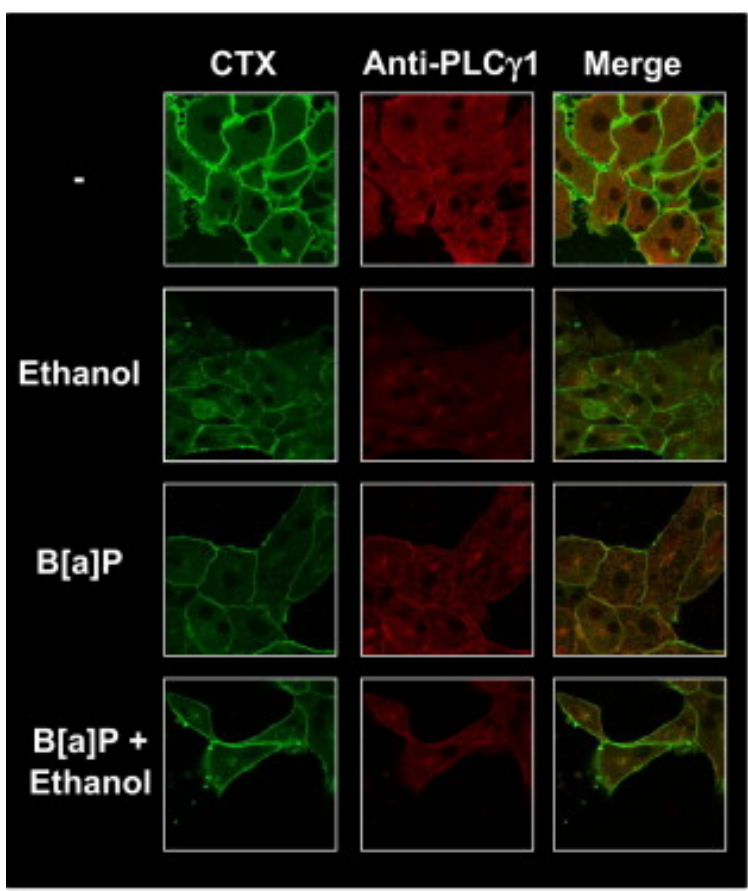

C
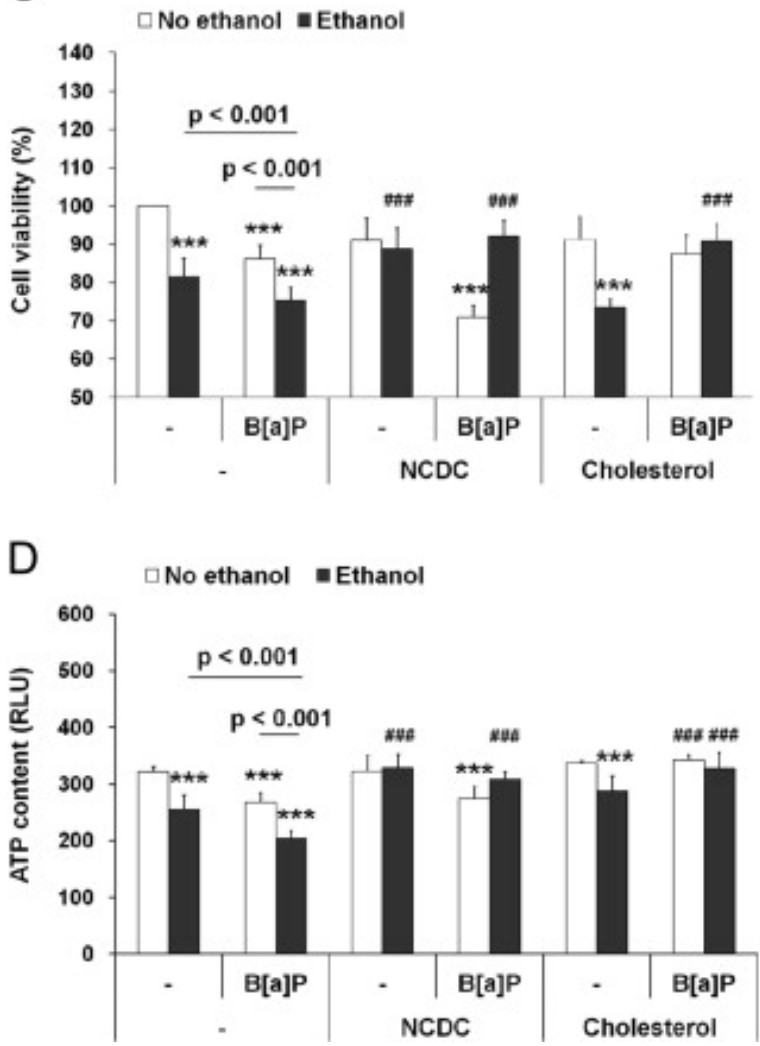

B

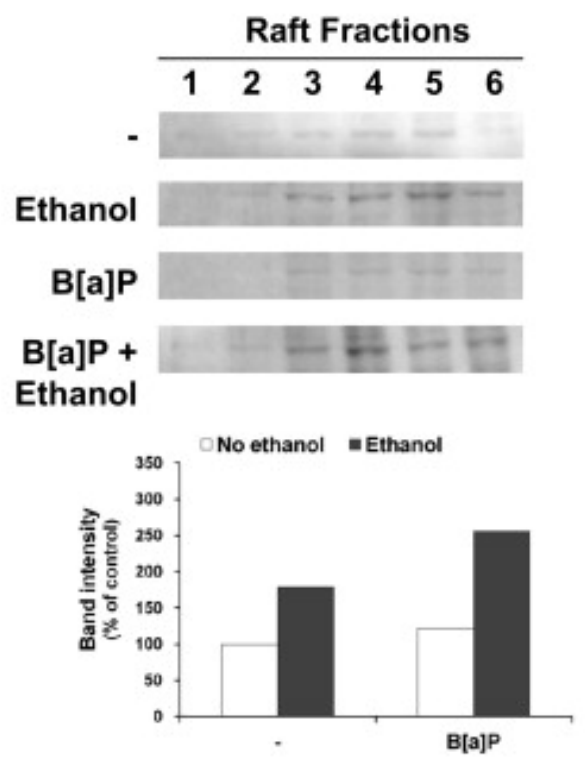

E With Cholesterol

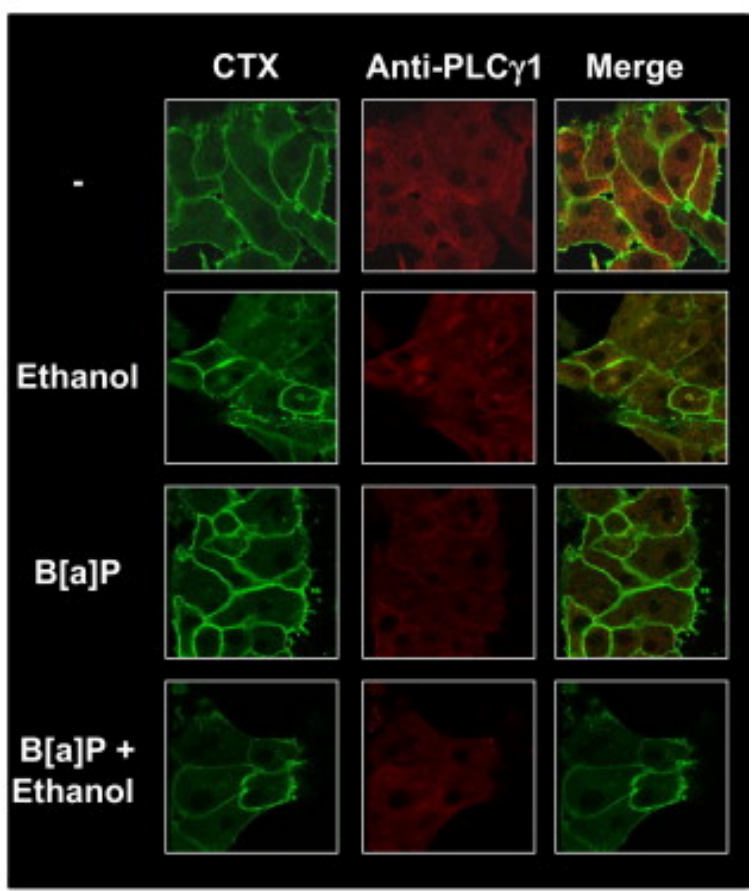

Figure 7. The phospholipase $\mathrm{C} \gamma 1$ translocation to lipid rafts induced by $\mathrm{B}[\mathrm{a}] \mathrm{P} / \mathrm{ethanol}$ co-exposure via a cholesterol depletion enhanced cell death. (A, E) Rat hepatocytes were co-stained by Alexafluor cholera toxin subunit B (CTX ; green fluorescence, left panels) and 
tetramethyl rhodamine isothiocyanate (TRITC)-conjugated antibody to phospholipase $\mathrm{C} \gamma 1$ (antiPLC $\gamma 1$; red fluorescence, middle panels). The merge of the images obtained by confocal fluorescence microscopy shows yellow areas (right panels) that represent colocalization of monosialotetrahexosylganglioside and PLC $\gamma 1$. One representative of three independent experiments is shown. (B) Lipid rafts were obtained after lysis of hepatocytes in ice-cold 1\% Triton X-100 and fractionation on a sucrose density gradient by ultracentrifugation. An equal protein amount of each fraction was submitted to western blotting for analysis of phospholipase $\mathrm{C} \gamma 1$ expression, followed by band densitometry (below the blots). One representative of three independent experiments is shown. Metabolically active viable hepatocytes were evaluated both by (C) the mitochondrial succinate dehydrogenase activity using a MTT assay and by (D) the ATP content using a luminescent assay. Primary rat hepatocytes were treated or not for 18 hours with $100 \mathrm{nM} \mathrm{B}[\mathrm{a}] \mathrm{P}$ before $50 \mathrm{mM}$ ethanol addition (or not) for a further 5-hours incubation time. Some cultures were pretreated for 30 minutes with $50 \quad \mu \mathrm{M}$ 2-nitro-4-carboxyphenyl-N,N-diphenylcarbamate (NCDC), a phospholipase $\mathrm{C} \gamma 1$ inhibitor, or, for 1 hour, with $50 \mu \mathrm{g} / \mathrm{ml}$ cholesterol. Values are given as means \pm SD of at least four independent experiments. Toxicant treated versus untreated cultures: $* * \mathrm{p}<0.01 ; * * * \mathrm{p}<0.001$. NCDC or cholesterol pretreated versus unpretreated cultures : \#p $<0.05 ; \# \# \mathrm{p}<0.01 ; \# \# \# \mathrm{p}<0.001$. 


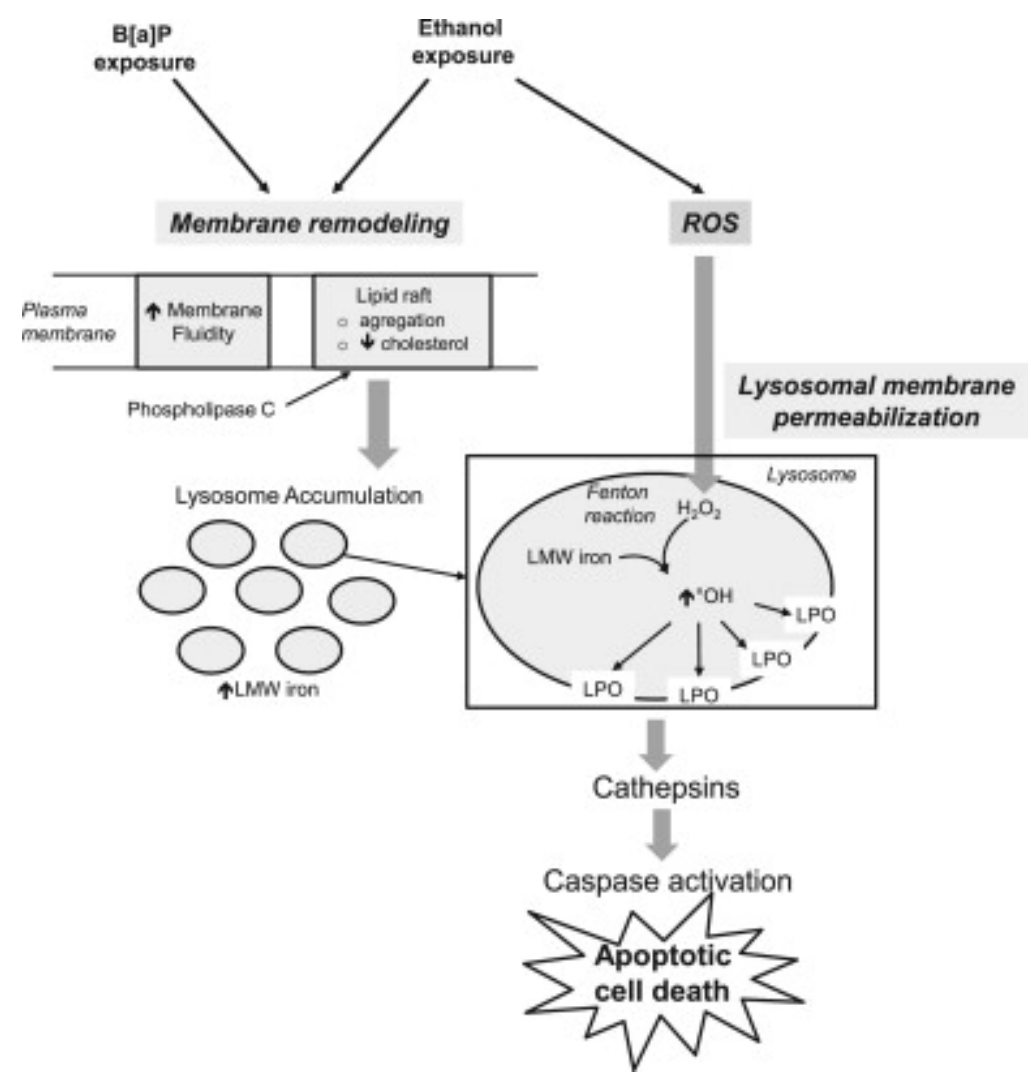

Figure 8. Proposed mechanism for the role of membrane remodeling and lysosome membrane permeabilization in the enhancement by ethanol of benzo[a]pyrene-induced oxidative stress and cell death. Both toxicants could induce plasma membrane remodeling, but with different complementary effects, that finally would promote an elevation of phospholipase $\mathrm{C}$ translocation into lipid rafts. Then, activation of phospholipase $\mathrm{C}$ would induce the accumulation of lysosomes and lead to an important elevation of LMW iron cellular content. Ethanol metabolism but not $\mathrm{B}[\mathrm{a}] \mathrm{P}$ would provide hydrogen peroxide to lysosomes, which, in turn, would trigger Fenton reaction and excessive hydroxyl radical production, thereby enhancing lysosomal lipid peroxidation and membrane permeabilization leading to the release of hydrolase capable of activating caspases. Thus, both toxicants may cooperate by similar and various mechanisms to induce an increase in lysosomal membrane permeabilization that could lead to cell death. 